MANNHEIM RESEARCH INSTITUTE For THE ECONOMICS OF AGING

KANN DIE RIESTER-RENTE DIE RENTENLÜCKE IN DER GESETZLICHEN

RENTE SCHLIEßEN?

Axel Börsch-Supan, Martin Gasche

๑) $\boldsymbol{m e a - M a n n h e i m ~ R e s e a r c h ~ I n s t i t u t e ~ f o r ~ t h e ~ E c o n o m i c s ~ o f ~ A g i n g ~}$

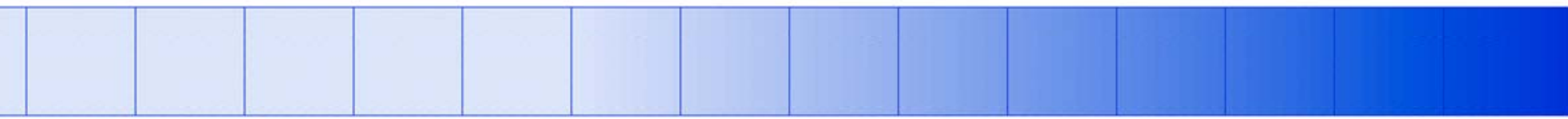

L13, 17_D-68131 Mannheim_Phone +49 621 181-2773/1862_Fax +49 621 181-1863_www.mea.uni-mannheim.de 


\title{
Kann die Riester-Rente die Rentenlücke in der gesetzlichen Rente schließen?
}

\author{
Axel Börsch-Supan \\ Martin Gasche ${ }^{1}$ \\ Mannheimer Forschungsinstitut Ökonomie und Demographischer Wandel (MEA) \\ Universität Mannheim ${ }^{2}$
}

Juli 2010

\begin{abstract}
Zusammenfassung
Mit der Rentenreform 2001 wurde die so genannte Riester-Rente geschaffen. Sie soll die Rentenlücke schließen, die durch die Anpassung der umlagefinanzierten gesetzlichen Rente an die demographische Entwicklung entstehen wird. In dieser Studie wird untersucht, ob dies gelingt und von welchen Faktoren dieses Gelingen abhängt. Es zeigt sich, dass unter den gängigen Annahmen die Riester-Rente beim Rentenzugang die Rentenlücke schließen kann, wenn $4 \%$ des Bruttoeinkommens in einen Riester-Vertrag gespart werden. Entscheidend sind vor allem die Verzinsung des Riester-Kapitals und die Höhe der Dynamisierung der RiesterRentenzahlung sowie die Ansparzeit. Weniger variabel reagiert das Riester-Rentenniveau auf eine Variation der Lebenserwartung, also auf die Rentenlaufzeit sowie auf die zeitliche Verteilung des individuellen Erwerbseinkommens über die gesamte Erwerbsphase. Soll die Rentenlücke nicht nur im Rentenzugangsjahr, sondern über die gesamte Rentenzeit eines Rentners geschlossen werden, reicht bei realistischen Lohnzuwachsraten ein RiesterBeitragssatz von 4\% erst für diejenigen Jahrgänge aus, die nach 2030 in Rente gehen.
\end{abstract}

JEL: H55, J18

Schlagwörter: Riester-Rente, Rentenlücke, Rentenreformen, Rentenniveau, Rente mit 67

\footnotetext{
${ }^{1}$ Wir danken Dr. Anette Reil-Held und Tabea Bucher-Koenen sowie Stefan Bergheimer für wichtige Hinweise und Kommentare.

${ }^{2}$ Das MEA ist ein Forschungsinstitut der Universität Mannheim, das sich zu etwa zwei Dritteln aus Drittmitteln der öffentlichen Forschungsförderung finanziert. Dafür sind wir dankbar. Wir danken ebenso dem Land BadenWürttemberg und dem Gesamtverband der Deutschen Versicherungswirtschaft für die Grundfinanzierung des MEA.

Kontakt: MEA; Universität Mannheim; L13,17; 68131 Mannheim; E-Mail: Gasche@mea.uni-mannheim.de.
} 


\section{Einleitung}

Mit den Rentenreformen 2001 und 2004 wurde beschlossen, das Niveau der gesetzlichen Rente graduell zu senken, um vor dem Hintergrund der demographischen Entwicklung die umlagefinanzierte Gesetzliche Rentenversicherung finanzierbar zu halten. Gleichzeitig wurde die so genannte Riester-Rente eingeführt. Die Riester-Rente ist eine private kapitalgedeckte Rentenversicherung auf freiwilliger Basis. Mit der Riester-Rente sollte die durch die Reform entstehende Rentenlücke geschlossen werden, so dass sich das Gesamtversorgungsniveau der Versicherten (gesetzliche Rente plus Riester-Rente) nicht verändert.

Damit die Riester-Rente trotz Freiwilligkeit flächendeckend abgeschlossen wird, wird sie durch die Zahlung von Zulagen oder durch einen Abzug der Sparbeiträge von der Steuerbemessungsgrundlage der Einkommensteuer gefördert. Um die volle Zulage zu erhalten, muss ein Mindestprozentsatz des Bruttoeinkommens eingezahlt werden. Dieser betrug im Jahr 2002 zunächst 1\% und wurde dann alle 2 Jahre in Stufen (sog. Riester-Treppe) auf 4\% im Jahr 2008, maximal jedoch nicht mehr als 2.100 Euro, erhöht. Nach nunmehr fast einem Jahrzehnt seit Verabschiedung der Riester-Reform ist die Frage nach wie vor aktuell, ob der „Riester-Beitragssatz“ von 4\% p.a. ausreicht, um die Rentenlücke zu schließen, die durch den Rückbau des umlagefinanzierten Systems entsteht.

Die hier vorgelegte Analyse enthält neben einer grundlegenden theoretischen Fundierung des Konzeptes der „Rentenlücke“ auch eine Aktualisierung der den Rentenreformen 2001 und 2004 zugrunde gelegten Berechnungen (z.B. Börsch-Supan et al. 2003, Rürup-Kommission 2003, Börsch-Supan et al. 2008), da sich die institutionellen und wirtschaftlichen Rahmenbedingungen seitdem geändert haben. So wurde mehrmals diskretionär in die Rentenanpassung eingegriffen. Zudem hat die Finanz- und Wirtschaftskrise auch in der Gesetzlichen Rentenversicherung ihre Spuren hinterlassen und im Bereich der Riester-Rente die Frage nach den zugrunde liegenden Zinsszenarien für die Berechnung der Riester-Renten neu gestellt.

Diese Studie zeigt, dass das Schließen der Rentenlücke zum Zeitpunkt des Renteneintritts außer vom monatlichen Sparbetrag entscheidend von der Verzinsung des Riester-Kapitals, der Höhe der Dynamisierung der Riester-Rentenzahlung sowie von der Ansparzeit abhängt. Weniger variabel reagiert das Riester-Rentenniveau auf eine Variation der Lebenserwartung sowie auf die zeitliche Verteilung des individuellen Erwerbseinkommens über die gesamte 
Erwerbsphase. Ob die Riester-Rente die Rentenniveaulücke schließen kann, hängt entscheidend von der unterstellten Lohnzuwachsrate ab. Je niedriger diese Rate ist, desto bedeutender ist die Riester-Rente relativ zum Lohneinkommen, und umso leichter kann die Lücke geschlossen werden.

Untersucht wird die Zielerreichung für zwei Zieldefinitionen. Nach der traditionellen Zieldefinition muss die Riester-Rente die Rentenlücke im Rentenzugangsjahr schließen. Nach unserer strengeren Zieldefinition muss die Lücke in jedem Jahr des Rentenbezugs geschlossen werden. Während der Zielerreichungsgrad bei Anwendung der einfachen Definition recht hoch ist, muss bei Anwendung der strengen Definition festgestellt werden, dass ein RiesterBeitragssatz von 4\% p.a. in der Regel nicht ausreicht, um die Rentenlücke nicht nur im Rentenzugangsjahr, sondern über die gesamte Rentenbezugszeit zu schließen.

Im Folgenden wird zunächst die Rentenlücke und die Rentenniveaulücke definiert (Abschnitt 2) und berechnet (Abschnitt 3). Vereinfacht ist die Rentenlücke der Prozentsatz, um den die gesetzliche Rente niedriger ausfällt als in einer Situation ohne die Rentenreformen 2001 und 2004. Im Abschnitt 4 werden die Berechnungsweise und die Determinanten der Riester-Rente vorgestellt. Dann wird für verschiedene Variationen dieser Determinanten errechnet, ob mit dem maximalen geförderten Sparbeitrag die Rentenlücke geschlossen werden kann. Konkret wird im fünften Abschnitt zunächst ein Basisszenario vorgestellt. Dann wird in den Abschnitten 6 bis 13 die Variation der Ergebnisse aufgezeigt, wenn im Vergleich zu diesem Basisszenario jeweils eine Annahme geändert wird. In Abschnitt 14 wird berechnet, wie viel der Rentenlücke durch eine Ausweitung der Erwerbszeit als Reaktion auf die Erhöhung des gesetzlichen Renteneintrittsalters („Rente mit 67“) geschlossen werden kann. Abschnitt 15 schließt die Studie mit einem Fazit ab.

\section{Definition der Rentenlücke}

Die Rentenreformen der Jahre 2001 und 2004 bewirken, dass die Rentensteigerungen hinter den Lohnsteigerungen zurückbleiben. Dadurch sinkt allmählich das Rentenniveau, definiert als die Relation der Rente zum Lohneinkommen, und die Rentenversicherung wird relativ zu einer Situation ohne Reformen finanziell entlastet, so dass sie die zusätzliche Belastung durch die Bevölkerungsalterung besser tragen kann. Die Dämpfung der Rentenentwicklung im Vergleich zur Lohnentwicklung wird in der Rentenanpassungsformel durch den sog. Riester- 
Faktor $R F$ und den Nachhaltigkeitsfaktor $N F$ bewirkt. Die Rentenanpassungsformel, die die Rentensteigerungsrate $\theta_{i}$ im Jahr $i$ bestimmt, lautet vereinfacht:

$$
\left(1+\theta_{i}\right)=\left(1+\omega_{i}\right) \cdot R F_{i} \cdot N F_{i},
$$

wobei $\omega_{i}$ die Zuwachsrate der rentenanpassungsrelevanten Löhngröße bezeichnet.

Sind der Riester-Faktor und Nachhaltigkeitsfaktor kleiner als eins, bleibt die Rentenanpassungsrate hinter der Lohnsteigerungsrate zurück. Mithin sinkt das Rentenniveau. ${ }^{3}$ Je öfter der Nachhaltigkeitsfaktor und der Riester-Faktor bis zum Zeitpunkt des Rentenzugangs angewendet wurden, desto größer ist der Unterschied zu einer Situation, in der es diese Dämpfungsfaktoren nicht gegeben hätte. Die in Euro ausgedrückte Rentenlücke kann somit definiert werden als der Unterschied in der Rentenhöhe zwischen einer Situation ohne die Dämpfungsfaktoren $R F$ und $N F$ und der tatsächlichen Situation mit diesen Dämpfungsfaktoren.

Für einen bestimmten Rentenanspruch - ausgedrückt durch eine bestimmte Anzahl von Entgeltpunkten - gilt, dass er mit der Rentenanpassungsrate wächst. Ausgehend vom Jahr der Reformen $R$ bis zu einem Jahr $z$, dem Rentenzugangsjahr, gilt für die Höhe des Rentenanspruchs im Jahr z:

(2) $\quad r_{z}=r_{R} \prod_{i=R+1}^{z}\left(1+\theta_{i}\right)$.

Hätte es die Rentendämpfungsfaktoren $R F$ und $N F$ nicht gegeben, hätte sich die Rentenhöhe wegen der Gleichungen (1) und (2) aus folgender Gleichung ergeben:

$$
r_{z}^{\text {ohne }}=r_{R} \prod_{i=R+1}^{z}\left(1+\omega_{i}\right)
$$

Setzt man die in Euro gemessene absolute Rentenlücke ins Verhältnis zum Rentenzahlbetrag, erhält man die relative Rentenlücke $R R L$, d.h. die prozentuale Abweichung der Rente beim Rentenzugang im Jahr $z$ im Falle der Reformen im Vergleich zur Rente im Jahr $z$, wenn es die Rentendämpfungsfaktoren nicht gegeben hätte:

$$
R R L_{z}=1-\frac{r_{z}}{r_{z}^{\text {ohne }}}=1-\prod_{i=R+1}^{z} \frac{\left(1+\theta_{i}\right)}{\left(1+\omega_{i}\right)}=1-\prod_{i=R+1}^{z} R F_{i} \cdot N F_{i} .
$$

Damit zeigt sich, dass die relative Rentenlücke unabhängig von individuellen Größen ist. Sie hängt nur vom Verhältnis der Lohnwachstumsrate zur Rentenanpassungsrate ab bzw. vom Beitragssatzfaktor und vom Nachhaltigkeitsfaktor. Somit ist die Rentenlücke als Prozentsatz des Rentenzahlbetrags für alle Rentner eines Zugangsjahres prozentual gleich groß.

\footnotetext{
${ }^{3}$ Von diversen Schutzklauseln wird zunächst abgesehen.
} 
Soll die Riester-Rente $p^{*}$ die Rentenlücke im Rentenzugangsjahr z schließen, muss gelten:

$$
p_{z}^{*}=r_{z}^{o h n e}-r_{z} .
$$

Wegen Gleichung (4) folgt daraus:

$$
p_{z}^{*}=r_{z} \frac{R R L_{z}}{1-R R L_{z}}=r_{z}\left[\prod_{i=R+1}^{z} \frac{\left(1+\omega_{i}\right)}{\left(1+\theta_{i}\right)}-1\right]=r_{z} \frac{1-\prod_{i=R+1}^{z} R F_{i} \cdot N F_{i}}{\prod_{i=R+1}^{z} R F_{i} \cdot N F_{i}} .
$$

Gleichung (6) macht deutlich, dass die Frage, ob die Riester-Rente die Rentenlücke schließen kann, maßgeblich auch von der unterstellten Entwicklung der Löhne abhängt. Die zur Schließung der Lücke erforderliche Riester-Rente ist umso höher, je höher die Lohnzuwachsrate $\omega_{i}$ ausfällt.

Es hat sich als praktisch erwiesen, die Rentenlücke als Prozentsatz des Lohneinkommens auszudrücken. Genau genommen stellt dieser Prozentsatz also die Rentenniveaulücke dar. Wir bezeichnen sie mit $R N L$, folgen aber dem allgemeinen Sprachgebrauch und nennen sie im Folgenden „Rentenlücke“, wenn keine Verwechslungen möglich sind. Sie entspricht der Abweichung des Bruttorentenniveaus mit Reformen bei Rentenzugang (d.h. $r_{z} / y_{z}$ ) vom Bruttorenteniveau ohne Reformen bzw. vom Bruttorentenniveau im Jahr $R$ der Reformen (d.h. $\left.r_{R} / y_{R}\right)$

$$
R N L_{z}=\frac{r_{R}}{y_{R}}-\frac{r_{z}}{y_{z}} .
$$

Für $\mathrm{r}_{\mathrm{z}} / \mathrm{y}_{\mathrm{z}}$ gilt wegen Gleichung (2):

$$
\frac{r_{z}}{y_{z}}=\frac{r_{R}}{y_{R}} \frac{\prod_{i=R+1}^{z}\left(1+\theta_{i}\right)}{\prod_{i=R+1}^{z}\left(1+\omega_{i}\right)} .
$$

Damit gilt für die Rentenniveaulücke:

$$
\begin{aligned}
& R N L_{z}=\frac{r_{R}}{y_{R}}\left[1-\prod_{i=R+1}^{z} \frac{\left(1+\theta_{i}\right)}{\left(1+\omega_{i}\right)}\right]=\frac{r_{R}}{y_{R}} R R L_{z} \text { oder } \\
& R N L_{z}=\frac{r_{z}}{y_{z}}\left[\prod_{i=R+1}^{z} \frac{\left(1+\omega_{i}\right)}{\left(1+\theta_{i}\right)}\right]=\frac{r_{z}}{y_{z}} \frac{R R L_{z}}{1-R R L_{z}} .
\end{aligned}
$$

Sie ergibt sich aus dem Rentenniveau zum Zeitpunkt der Reformen multipliziert mit der relativen Rentenlücke oder aus dem Rentenniveau im Rentenzugangsjahr multipliziert mit dem Rentenlückenfaktor. Sie hängt damit von der Höhe der individuellen Rentenansprüche in 
Relation zum individuellen Einkommen ab. Man kann die Größe $r_{R} / y_{R}$ auch als Standardrentenniveau auffassen, definiert als den Rentenanspruch in Höhe von 45 Entgeltpunkten in Relation zum Durchschnittseinkommen im Reformjahr $R$.

Die Riester-Rente, die die Rentenniveaulücke schließt, ergibt sich aus den Gleichungen (6) und (10) als:

(11) $\quad p_{z}^{*}=R N L_{z} \cdot y_{z}$

Das erforderliche Riester-Rentenniveau $p^{*}{ }_{z} / y_{z}$ muss mithin der Rentenniveaulücke entsprechen.

Das Ziel, die Rentenlücke bzw. die Rentenniveaulücke zu schließen, kann in einer einfachen Form und einer strengen Form formuliert werden. Nach der einfachen Zieldefinition muss die Lücke im Rentenzugangsjahr z geschlossen sein. Dies entspricht den meisten bisherigen Analysen. ${ }^{4}$ In der strengen Zieldefinition soll die Riester-Rente in jedem Jahr des Rentenbezugs die Lücke schließen. Diese Definition entspricht der Logik der Riester-Rente als ersetzende private Altersvorsorge, mag aber zu streng sein, weil in hohem Alter die Konsumausgaben typischerweise deutlich sinken. In dieser Studie wird die Zielerreichung beider Zieldefinitionen untersucht und diskutiert.

\section{Quantifizierung der Rentenlücke}

Zur Quantifizierung der Rentenlücke muss die Entwicklung des Rentenniveaus seit dem Reformjahr 2001 und für die Zukunft bekannt sein. Um Projektionen in die Zukunft machen zu können, ist ein Simulationsmodell der Rentenversicherung erforderlich, mit dem der aktuelle Rentenwert unter Berücksichtigung der Rentenanpassungsformel berechnet wird. Daraus kann dann das Rentenniveau bestimmt werden. Verwendet werden hier die Ergebnisse aus Gasche (2010). Die wichtigsten dort getroffenen Annahmen werden im Folgenden kurz zusammengefasst:

- Die Löhne entwickeln sich gemäß den Angaben des Rentenversicherungsberichts 2009. ${ }^{5}$ Dort wird angenommen, dass die Lohnzuwachsrate bis 2020 kontinuierlich auf 3\% p.a. ansteigt. Ab 2020 wird eine konstante Zuwachsrate von 3\% p.a. unterstellt.

- Der Nachhaltigkeitsfaktor entwickelt sich gemäß Rentenversicherungsbericht $2009 .{ }^{6}$ Ab 2024 entwickelt sich der Rentnerquotient so wie in Börsch-Supan, Gasche, Wilke (2009) angenommen.

\footnotetext{
${ }^{4}$ Vgl. z.B. Börsch-Supan, Bucher-Koenen, Reil-Held, Wilke (2008).

${ }^{5}$ Vgl. BMAS (2009).
} 
- Der Riester-Faktor wird durch die Riester-Treppe bestimmt und durch die sich aus dem Modell ergebenden Beitragssatzänderungen.

Andere Annahmen führen entsprechend zu einer anderen Rentenlücke. Wie oben gezeigt wurde, hängt die Lücke entscheidend von der Differenz zwischen der Lohnwachstumsrate und der Rentenanpassungsrate ab und diese wiederum vom Riester-Faktor und vom Nachhaltigkeitsfaktor, letztlich also von unterschiedlichen Szenarien hinsichtlich der zukünftigen Entwicklung der gesetzlichen Rentenversicherung. Geht man beispielsweise von ungünstigeren Szenarien bezüglich der Entwicklung der Rentnerzahl in Relation zu den Beitragszahlern aus, dann dämpft nicht nur der Nachhaltigkeitsfaktor stärker, sondern es kommt auch zu einem stärkeren Anstieg des Beitragssatzes. Eine Beitragssatzerhöhung um einen Prozentpunkt sorgt für eine um 1,3 bis 1,4 Prozentpunkte stärkere Rentendämpfung. Entsprechend größer würde die Rentenlücke ausfallen.

In dieser Studie soll grundsätzlich nur ein Szenario der GRV-Entwicklung mit einer entsprechenden Rentenlücke zugrunde gelegt werden. Es wird dann untersucht, wie unterschiedliche Annahmen über die Riester-Rente sich darauf auswirken, wie und ob diese Lücke geschlossen wird. Eine Ausnahme bildet der Abschnitt 13, wo die Rentenlücke für verschiedene Lohnannahmen dargestellt wird.

In Abbildung 1 wird die kumulierte Wirkung des Nachhaltigkeitsfaktors und des Riesterfaktors ohne die Wirkung diverser Schutzklauseln dargestellt. Die alte Schutzklausel hat in den Jahren 2005 und 2006 verhindert, dass die Renten aufgrund der Dämpfungswirkung des Nachhaltigkeitsfaktors und des Riester-Faktors gesenkt werden mussten. Im Jahr 2009 wurde die Rentengarantie (neue Schutzklausel) angewendet, die generell ein Sinken der Renten ausschließt, auch wenn die Löhne sinken sollten. Da die durch die Schutzklauseln unterbliebenen Rentendämpfungen nachgeholt werden sollen, wird nicht die kumulierte Höhe der Rentenlücke, sondern nur ihr zeitliches Auftreten beeinflusst.

Es zeigt sich, dass die Rentenlücke relativ zum Rentenzahlbetrag im Jahr 2030 14,4\% beträgt und im Jahr 2040 15,9\%. Damit ist die gesetzliche Rente im Jahr 2030 um 14,4\% geringer, als sie ohne Dämpfungsfaktoren gewesen wäre. Die Rentenlücke als Anteil des Lohneinkommens, d.h. die Rentenniveaulücke, ergibt sich, wenn man die relative Rentenlücke mit dem Standardrentenniveau von 48,4\% zum Zeitpunkt der Reformen multipliziert. Sie beträgt im Jahr 2030 7,0\% und im Jahr 2040 7,7\% (Abbildung 2).

\footnotetext{
${ }^{6}$ Vgl. BMAS (2009), Übersicht B17.
} 


\section{Abbildung 1: Kumulierter Nachhaltigkeitsfaktor und kumulierter Riester-Faktor ohne Berücksichtigung der Schutzklauseln ${ }^{7}$}

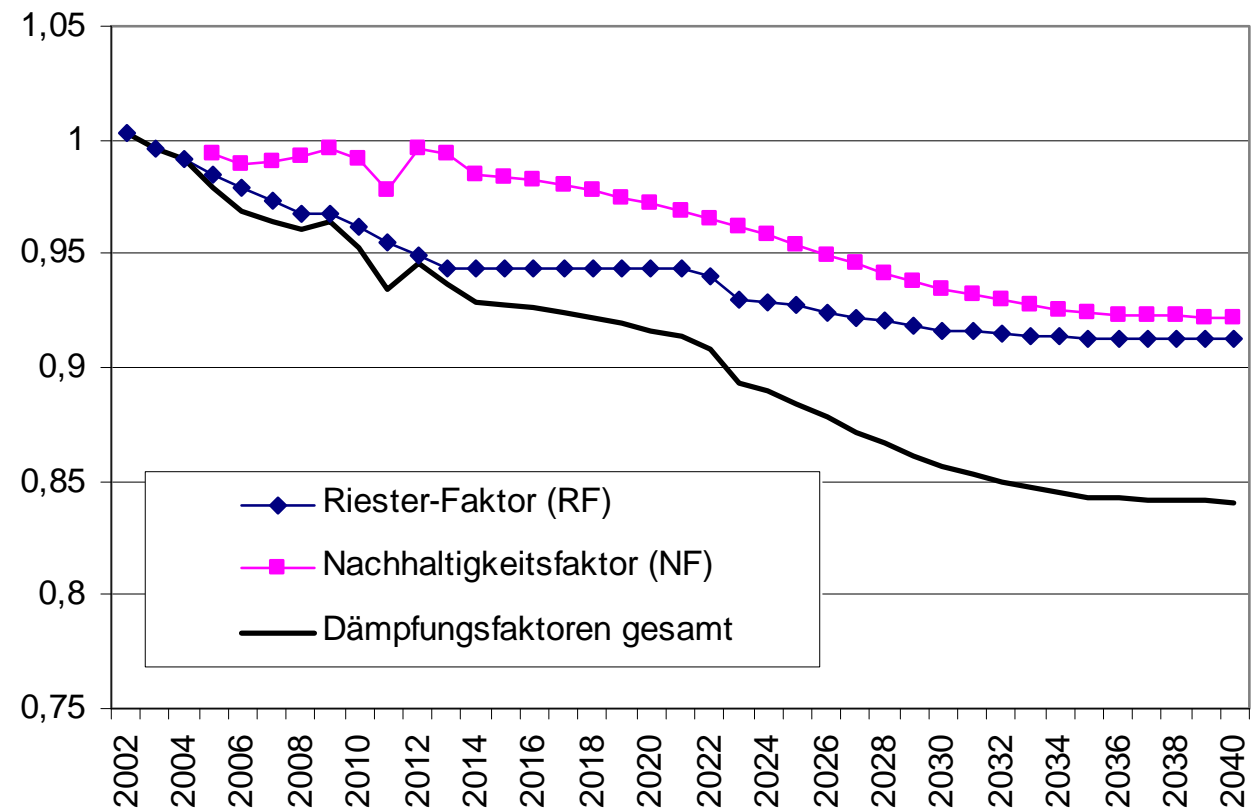

Quelle: eigene Berechnungen

\section{Abbildung 2: Relative Rentenlücke und Rentenniveaulücke ohne Berücksichtigung der Schutzklauseln}

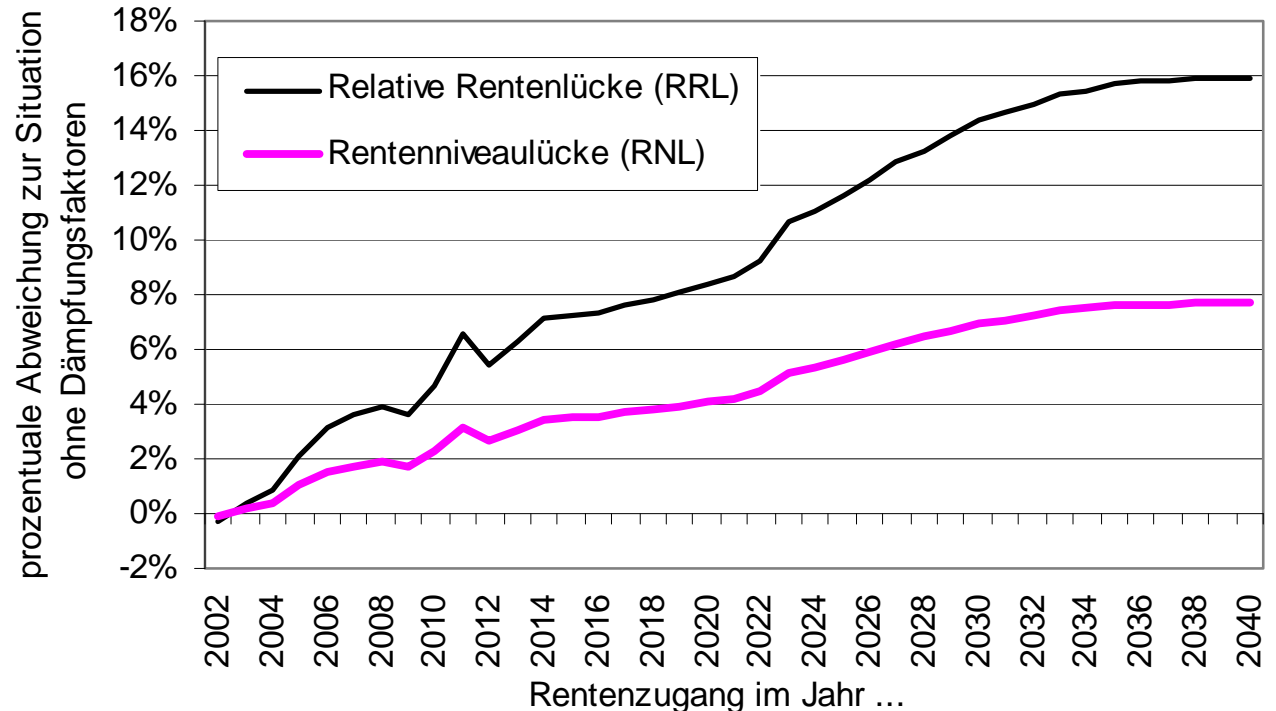

Quelle: eigene Berechnungen

Um auch die Wirkung der Schutzklauseln für die Rentenlücke zu berücksichtigen, werden zur Berechnung der Rentenlücke die aktuellen Rentenwerte aus Gasche (2010) zugrunde gelegt.

\footnotetext{
${ }^{7}$ Im Riester-Faktor wirken sich Beitragssatzsenkungen im nächsten Jahr rentensteigernd und Beitragssatzerhöhungen rentensenkend aus. Die für den dargestellten Verlauf des Riester-Faktors unterstellten Beitragssatzänderungen wurden Gasche (2010) entnommen.
} 
Da die rentensenkende Wirkung der Reformen 2001 und 2004 durch das Wirken der alten und der neuen Schutzklausel (2005, 2006 und 2010) und des Aussetzens der Riester-Treppe in der Rentenanpassungsformel (2008 und 2009) bisher noch nicht zum Tragen gekommen ist und die Finanzkrise die Lohneinkommen beeinträchtigt hat, ergibt sich zunächst sogar eine negative Renten(niveau)lücke. Mit dem in den Berechnungen unterstellten Nachholen der Rentendämpfungen bis 2016 wird der rentenniveausenkende Effekt der Reformen aber erreicht, so dass die Rentenniveaulücke bis auf knapp 8\% im Jahr 2040 anwächst (Abbildung 3). Die gesetzliche Rente ist dann rund 16\% niedriger, als wenn die Renten mit der Lohnrate angestiegen wären, d.h. wenn die Reformen sich nicht rentendämpfend ausgewirkt hätten.

Abbildung 3: Relative Rentenlücke und Rentenniveaulücke mit Berücksichtigung der Schutzklauseln

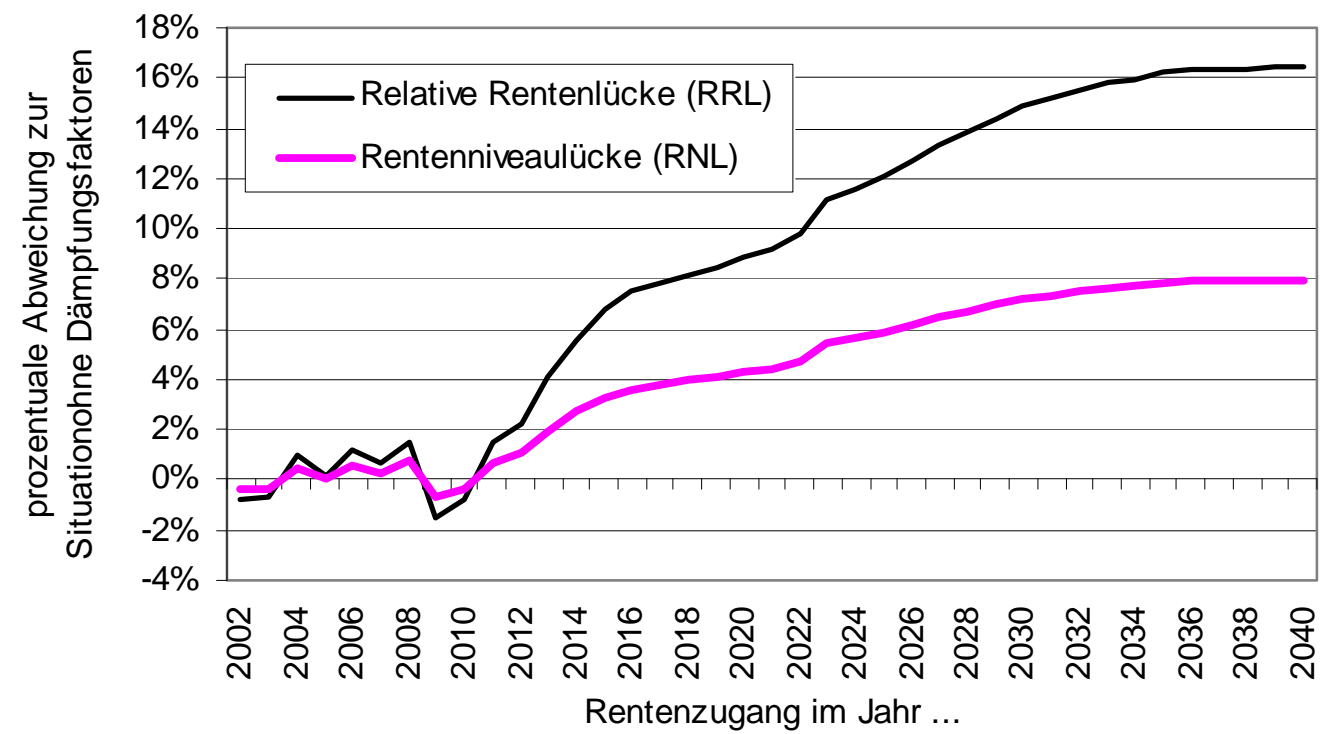

Quelle: eigene Berechnungen

\section{Berechnung der Riester-Rente}

Grundsätzlich wird die Riester-Rente in dieser Analyse wie eine Rentenversicherung konstruiert, die ab einem bestimmten Alter eine Rente bis zum Lebensende des Versicherten zahlt („Annuität“). Das gesamte gesparte Kapital wird also auf die Rentenlaufzeit verteilt, von Einmalauszahlungen z.B. zum Rentenbeginn wird abgesehen. Dem liegt der grundsätzliche Zweck der Riester-Rente zugrunde, im Alter ein regelmäßiges Einkommen zu generieren.

Es wird angenommen, dass in einem Jahr A mit dem Riester-Sparen begonnen wird und dann in jedem Jahr ein Betrag $S$ angespart wird, der mit der Rate $\eta_{j}$ verzinst wird. Es wird bis zum 
Jahr vor dem Renteneintritt z-1 gespart, so dass die Ansparzeit z-1-A beträgt. Das für die Rentenphase gesparte Riester-Kapital berechnet sich somit als:

(12) $\quad W_{z-1}=\sum_{i=A}^{z-1}\left[S_{i} \prod_{j=i}^{z-1}\left(1+\eta_{j}\right)\right]$.

Der Sparbetrag ist ein Anteil des Bruttoeinkommens $y$, das mit der Rate $\omega$ wächst, so dass sich aus Gleichung (12) ergibt:

$$
W_{z-1}=\sum_{i=A}^{z-1}\left[b_{i} y_{A} \prod_{j=i}^{z-1}\left(1+\omega_{j}\right)\left(1+\eta_{j}\right)\right] . \quad \text { mit } \omega_{A}=0
$$

und $b_{i}$ als „Riester-Beitragssatz“ im Jahr $i$.

Das angesparte Kapital wird nun über die Rentenlaufzeit $T$-z, die der durchschnittlich zu erwartenden Restlebenserwartung entspricht, in jährliche Rentenzahlungen aufgeteilt. Die Rentenzahlung im Rentenzugangsjahr ist $p_{z}$. Die Rentenzahlung wird mit einer Rate $\delta$ dynamisiert. Der Barwert der Rentenzahlungen zum Zeitpunkt z-1 entspricht dem gesparten Kapital $W_{z-1}$ :

$$
W_{z-1}=p_{z} \sum_{i=z}^{T} \frac{\prod_{j=z}^{i}\left(1+\delta_{j}\right)}{\prod_{j=z}^{i}\left(1+\eta_{j}\right)} .
$$

Somit wird gemäß den Gleichungen (13) und (14) die Riester-Rente im Rentenzugangsjahr z durch folgende Gleichung bestimmt:

$$
p_{z}=\frac{\left[\sum_{i=A}^{z-1}\left[b_{i} y_{A} \prod_{j=i}^{z-1}\left(1+\omega_{j}\right)\left(1+\eta_{j}\right)\right]\right]}{\left[\sum_{i=z}^{T} \prod_{j=z}^{i} \frac{\left(1+\delta_{j}\right)}{\left(1+\eta_{j}\right)}\right]} .
$$

Die maßgeblichen Determinanten sind somit:

- Der Zinssatz $\eta_{j}$ : Je höher die Verzinsung desto höher ist ceteris paribus die RiesterRente.

- Die Dynamisierungsrate $\delta_{j}$ : Je höher die Dynamisierung während der Rentenphase, desto geringer ist die Riester-Rente im Zugangsjahr.

- Die Restlebenserwartung bei Renteneintritt im Jahr $T-z$ : Je länger die Lebenserwartung, also die Rentenbezugszeit ist, desto geringer ist die Riester-Rente. 
- Die Ansparzeit $z-1-A$ : Je länger die Ansparzeit, desto höher das gesparte Kapital und damit die Riester-Rente.

- Der Riester-Beitragssatz $b_{i}$ : Je höher der Beitragssatz, desto höher die Riester-Rente.

- Das Einkommen $y_{A}$ und die Einkommensentwicklung $\omega_{j}$ : Je höher das Einkommen im Anfangsjahr und je stärker der Einkommensanstieg, desto höher ist die RiesterRente.

\section{Basisszenario}

Die Antwort auf die Frage, ob die Riester-Rente die Rentenlücke schließen kann, wird sehr stark von den Annahmen über die Höhe der obigen Determinanten bestimmt. Deshalb wird im Folgenden zunächst ein Basisszenario mit einer bestimmten plausiblen Annahmenkombination berechnet. Im zweiten Schritt werden in Sensitivitätsrechnungen die Änderungen der Ergebnisse präsentiert, wenn man eine Basisannahme variiert. Dem Basisszenario liegen folgende Annahmen zugrunde:

- Betrachtet wird ein Standardrentner, der in jedem Jahr das Durchschnittseinkommen verdient und 45 Jahre Beiträge bezahlt, also 45 Entgeltpunkte erworben hat. Diese Person geht mit 65 Jahren abschlagsfrei in Rente.

- Das Riester-Kapital verzinst sich mit nominal 4,5\% pro Jahr. Der Zins im Basisszenario ist damit an der Nettoverzinsung von Lebensversicherungen orientiert, die im Zeitraum 2002 bis 2008 durchschnittlich 4,7\% betrug. Die Verzinsung von Lebensversicherungen ist auch ein gutes Maß für die Verzinsung der Riester-Verträge, da der weitaus größte Teil der Riester-Verträge Versicherungen sind.

- In den Riester-Vertrag wird im jedem Jahr der für die maximale Förderung erforderlich Satz eingezahlt, beginnend mit 1\% des Bruttojahreseinkommens 2002 und dann alle zwei Jahre in Ein-Prozent-Schritten auf 4\% im Jahr 2008 ansteigend. Ab 2008 bleibt dieser „Riester-Beitragssatz“ bei $4 \%$ konstant. $^{8}$ Damit steigt mit dem Rentenzugangsjahr die Anzahl der Ansparjahre in den Riestervertrag. Die Ansparjahre errechnen sich aus dem Rentenzugangsjahr abzüglich 2002.

\footnotetext{
${ }^{8}$ In den Berechnungen wird der Förderhöchstsparbetrag von 2.100 Euro nicht berücksichtigt. Es wird vielmehr implizit angenommen, dass er im Zeitverlauf erhöht wird, so dass er für den Durchschnittseinkommensbezieher nicht beschränkend wirkt. Würde eine solche Dynamisierung nicht stattfinden, würde der Durchschnittseinkommensbezieher bei einem Riester-Beitragssatz von 4\% etwa im Jahr 2030 den Betrag von 2.100 Euro übertreffen.
} 
- Im Alter von 65 Jahren wird das gesparte Kapital für die erwarte Restlebensdauer eines durchschnittlichen Individuums verrentet. Der Rentenzahlbetrag wird mit einer Rate von 1,5\% dynamisiert, was man als Inflationsschutz interpretieren kann.

- Für die Restlebensdauer werden die ferneren Lebenserwartungen eines 65-Jährigen gemäß der MEA-eigenen Bevölkerungsvorausberechnung 3W1,5 unterstellt. ${ }^{9}$ Die Restlebenserwartung einer 65-jährigen Person beträgt im Jahr 2008 18,7 Jahre und im Jahr 2040 rund 24,0 Jahre.

- Die Kosten belaufen sich in jedem Jahr auf $10 \%$ der Sparrate. ${ }^{10}$ In der Auszahlungsphase fallen keine Kosten an.

- Das hypothetische Referenzrentenniveau ohne die Reformen ist 48,4\%, dem Bruttorentenniveau des Reformjahres 2001. Die Rentenniveaulücke ergibt sich als Differenz zu diesem Referenzniveau.

Auf Basis dieser Annahmen werden die Rentenniveaulücke (im Folgenden vereinfachend, wie in Abschnitt 2 erläutert, „die Rentenlücke“) und das Riester-Rentenniveau berechnet, welche in Abbildung 4 als Anteil des durchschnittlichen Lohneinkommens dargestellt sind. Es zeigt sich, dass in jedem Rentenzugangsjahr die Rentenlücke durch die Riester-Rente entweder vollständig oder zumindest zu 95\% geschlossen wird. Nur in den Rentenzugangsjahren 2016 und 2017 ist der Abdeckungsgrad mit 86\% etwas niedriger. Bis zum Jahr 2040 beträgt das Riester-Rentenniveau gut 10\%, so dass die Riester-Rente als dritte Säule der Altersvorsorge rund ein Fünftel des Versorgungsniveaus ausmacht (Abbildung 5). Somit kann man festhalten, dass die Riester-Rente bei Zugrundelegung der einfachen Zieldefinition, die Lücke im Rentenzugangsjahr zu schließen, einen sehr hohen Zielerreichungsgrad aufweist.

\footnotetext{
${ }^{9}$ Vgl. Börsch-Supan und Wilke (2009). Die neueste Projektion des Statistischen Bundesamtes in der Version L2 (,starker Anstieg“) kommt dieser MEA-Prognose sehr nahe. Vgl. Statistisches Bundesamt (2009).

${ }^{10}$ Dies entspricht den Annahmen, die auch von der Rürup-Kommission und im Rentenversicherungsbericht bei der Berechnungen des Gesamtversorgungsniveaus unterstellt wurden. Vgl. Rürup-Kommission (2003), S. 108, Tabelle 3-11 und BMAS (2009), Übersicht B8.
} 


\section{Abbildung 4: Rentenlücke und Riester-Rentenniveau im Basisszenario}

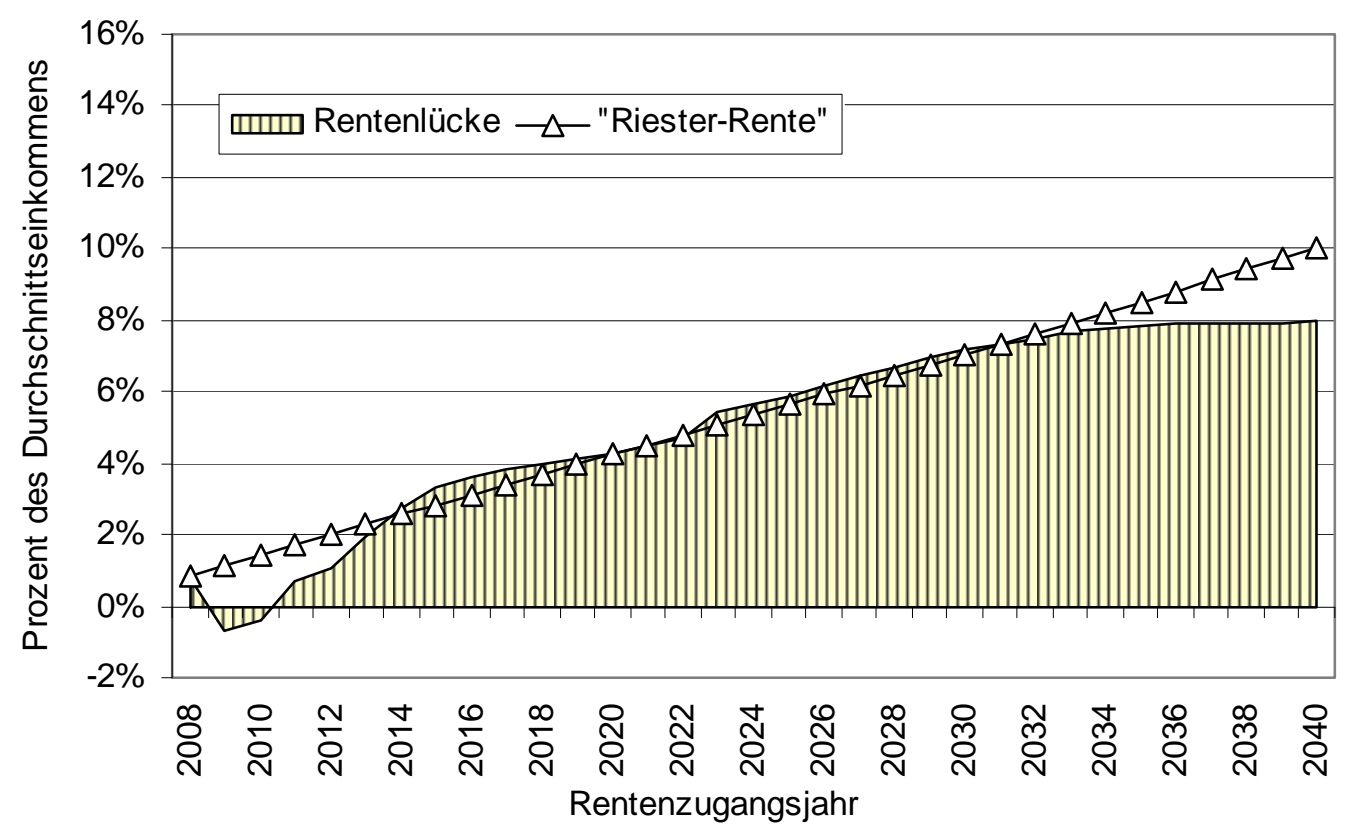

Quelle: eigene Berechnungen.

Abbildung 5: Rentenniveau der gesetzlichen Rente und Riester-Rentenniveau im Basisszenario

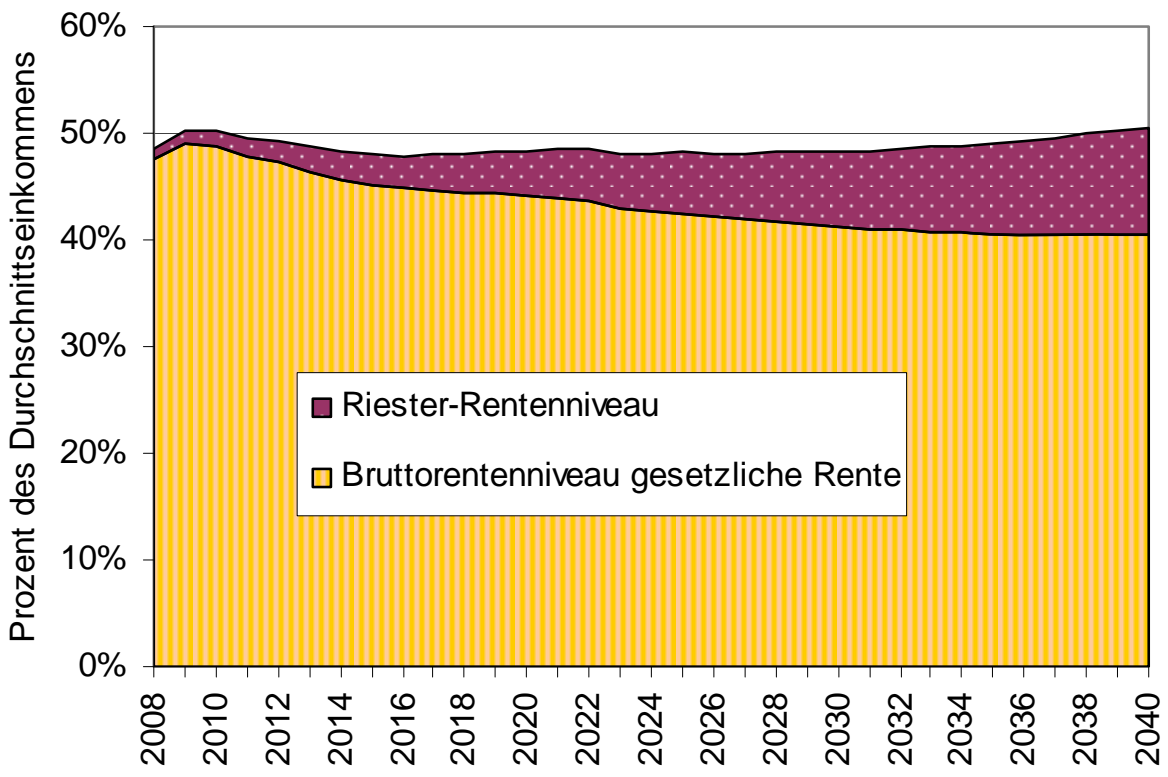

Rentenzugang im Jahr ...

Quelle: eigene Berechnungen.

Wendet man die strenge Zieldefinition an und verlangt, dass die Lücke nicht nur beim Rentenzugang, sondern während der gesamten Rentenzeit eines Individuums geschlossen wird, dann ergibt sich ein anderes Bild. Denn bei der strengen Zieldefinition muss das Gesamtrentenniveau bestehend aus GRV-Rente und Riester-Rente in jedem Jahr des 
Rentenbezugs mindestens das Niveau des Jahres vor der Reform, also 48,4\% des Bruttorentenniveaus erreichen. In Abbildung 6 ist dies als graue waagrechte Linie dargestellt. Der Verlauf des Rentenniveaus während der Rentenbezugszeit hängt von der Rentenzuwachsrate der gesetzlichen Rente und der Riester-Rente im Vergleich zur Entwicklung der Durchschnittslöhne ab. Die durchgezogene schwarze Linie in Abbildung 6 zeigt die Entwicklung des Bruttorentenniveaus der gesetzlichen Rente für den Fall, dass keine Riester-Rente abgeschlossen wurde bzw. für diejenigen Rentnerjahrgänge, die schon vor 2002 in Rente gegangen sind. Das Bruttorentenniveau sinkt kontinuierlich, weil die gesetzliche Rente mit einer geringeren Rate als die Lohneinkommen wächst. Hat man zusätzlich zur gesetzlichen Rente eine Riester-Rente abgeschlossen, kann über die gesamte Rentenbezugszeit eine höheres Rentenniveau erreicht werden, das umso höher ausfällt, je später das Rentenzugangsjahr ist. Aber auch das Gesamtrentenniveau (GRV+Riester) sinkt während der Rentenbezugszeit, da die Gesamtrente nicht so schnell zunimmt, wie das Durchschnittseinkommen. In allen betrachteten Fällen (Rentenzugang 2010, 2020, 2030 und 2040) rutscht das Gesamtrentenniveau während der Rentenbezugszeit unter das Referenzniveau von 48,4\% (Abbildung 6). Somit kann bei Anwendung der strengen Zieldefinition die Riester-Rente die Lücke nicht schließen. Allerdings hängt dieses Ergebnis sehr stark von der unterstellten Lohnzuwachsrate ab. Im Basisszenario wurde die recht optimistische langfristige Zuwachsrate von 3\% p.a. unterstellt. In Abschnitt 13 wird diese Annahme variiert.

Zudem muss man sich klar machen, dass das strenge Ziel, die Lücke über die ganze Rentenbezugszeit zu schließen, eine Ungleichbehandlung unterschiedlicher Rentnergenerationen impliziert, da es für die Rentner im Rentenbestand, also Personen, die vor 2002 in Rente gingen, nicht gilt. Diese Rentner müssen auch in ihrer Rentenphase eine Reduktion ihres Rentenniveaus, also der Relation ihrer Rente zum jeweiligen Durchschnittseinkommen hinnehmen, weil sie keine Riester-Rente haben. Für diese Rentner soll und kann diese Lücke aber nicht geschlossen werden. ${ }^{11}$ Insofern ist das Ziel, mit der Riester-Rente die Lücke über die gesamte Bezugszeit zu schließen, sehr weitgehend.

\footnotetext{
${ }^{11}$ Ein Rentner, der zum Beispiel im Jahr 2002 in Rente gegangen ist und bis 2020 lebt, hat keine Riester-Rente, muss aber bis 2020 die Rentenmindersteigerungen im Vergleich zur Lohnentwicklung, also die GRVRentenniveausenkung zwischen 2002 und 2020 gemäß Abbildung 6, hinnehmen. Ein Schließen dieser Lücke ist nicht vorgesehen.
} 


\section{Abbildung 6: Rentenniveau während der Rentenbezugszeit für unterschiedliche Rentenzugangsjahre}

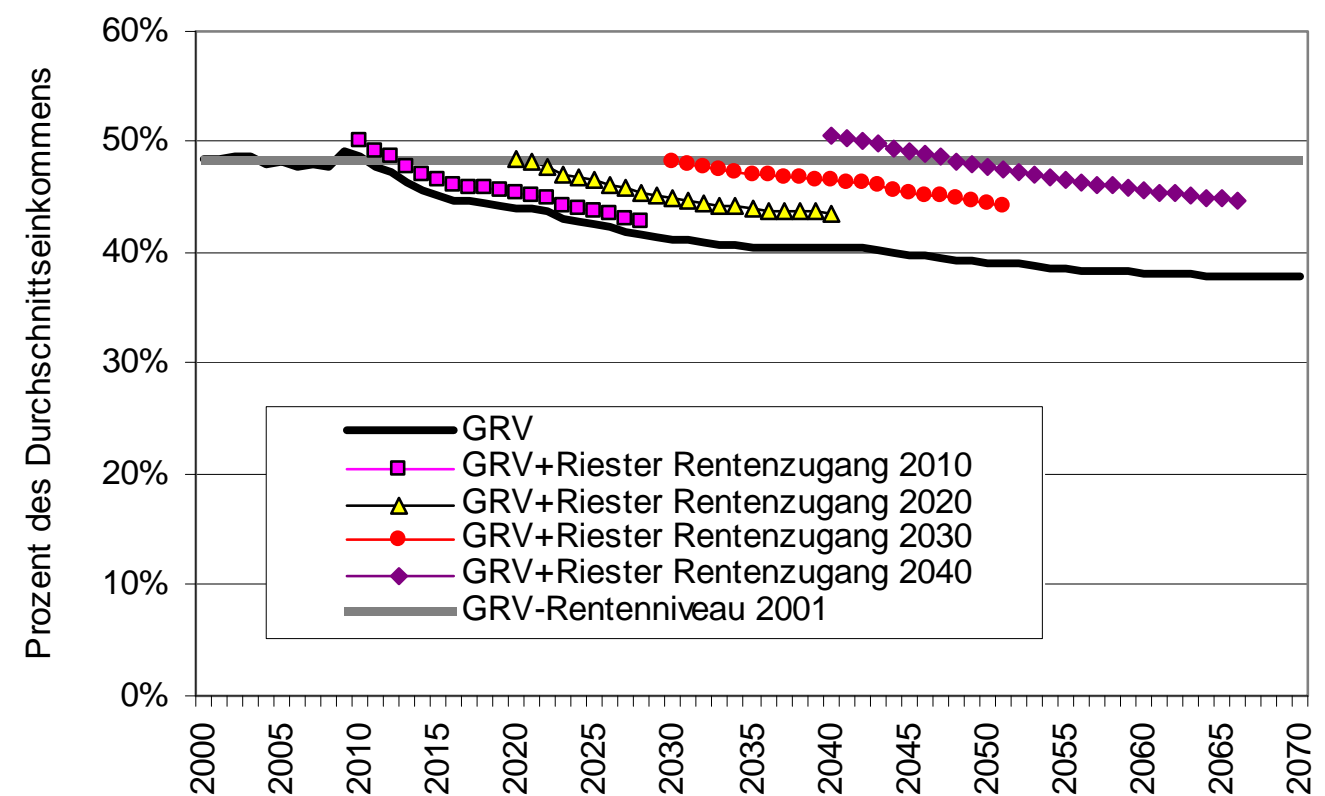

Quelle: eigene Berechnungen.

\section{Abhängigkeit vom Zinssatz}

Um die Sensibilität der Ergebnisse im Basisszenario vom unterstellten Zinssatz zu demonstrieren, werden nun alternative Zinsszenarien unterstellt. Zum einen werden alternative konstante Zinssätze von 6\% und 3\% angenommen. Der Zins im Basisszenario und auch die durchschnittliche Nettoverzinsung von Lebensversicherungen im Zeitraum 2002 bis 2008 von 4,7\% liegen damit dazwischen. Zudem wird ein variabler Zins unterstellt, der die Abhängigkeit der Kapitalrendite von der demographischen Entwicklung berücksichtigen soll. Unterstellt wird, dass der Zins von 5\% im Jahr 2002 auf 4\% im Jahr 2050 sinkt. Der Zinseinbruch im Jahr 2008 durch die Finanzkrise wird ebenfalls berücksichtigt, indem für das Jahr 2008 eine Verzinsung von -4,3\% angenommen wird (Abbildung 7). Damit sind die Wertverluste berücksichtigt, die sich bei den Riester-Investmentfonds ergeben haben. ${ }^{12}$

\footnotetext{
${ }^{12}$ Der Zinssatz im Jahr 2008 ist ein mit den Anteilen der Fonds, Versicherungsverträge und Banksparpläne an der Gesamtzahl der Riester-Verträge gewichteter Durchschnittszins. Vgl. dazu Börsch-Supan, Gasche und Ziegelmeyer (2009), Abschnitt 4.2 und Tabelle 2.
} 


\section{Abbildung 7: Alternative Verzinsung des Riester-Kapitals}

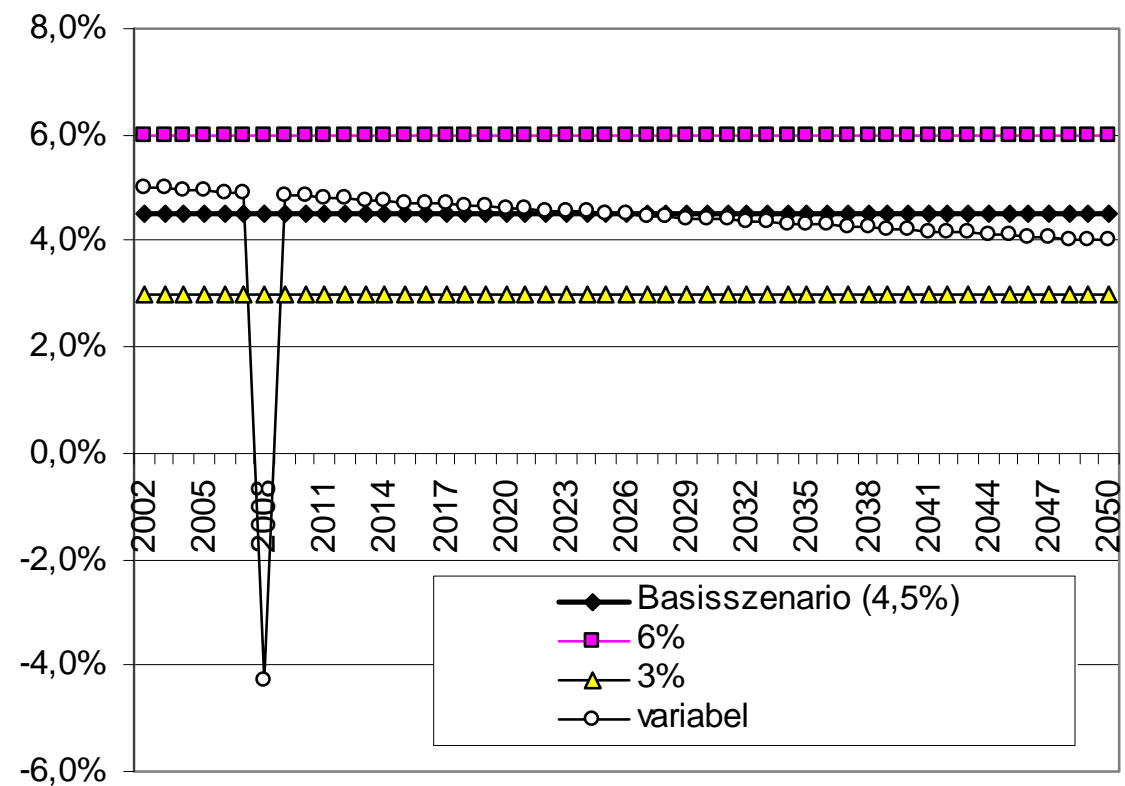

Quelle: eigene Berechnungen.

Eine höhere Verzinsung des Riester-Kapitals erlaubt es, eine höhere Rente zu zahlen. Insofern wird die Rentenlücke im Rentenzugangsjahr bei einem Zinssatz von nominal 6\% mehr als geschlossen (Abbildung 8). Im Jahr 2040 ist das Riester-Renteniveau sogar doppelt so groß wie die Rentenlücke. Ein Zinssatz von 3\% dagegen führt dazu, dass das Riester-Rentenniveau deutlich geringer ausfällt als im Basisszenario und die Lücke nicht geschlossen werden kann. Bei einer variablen Verzinsung, die die Auswirkungen der Finanzkrise und die demographische Entwicklung berücksichtigt, wird die Lücke dagegen nahezu vollständig geschlossen. Insgesamt zeigt sich eine sehr starke Abhängigkeit vom unterstellten Zinssatz.

Wendet man die strenge Zieldefinition an, ergibt sich bei einer Verzinsung von 6\% ein hoher Zielerreichungsgrad etwa ab Rentenzugang 2030 (Abbildung 9). Die Rentenlücke kann dann über die gesamte Rentenbezugszeit geschlossen werden. Vorher ist der Zinseszinseffekt noch nicht ausreichend zum Tragen gekommen. 
Abbildung 8: Rentenlücke und Riester-Rentenniveau in Abhängigkeit von der Verzinsung

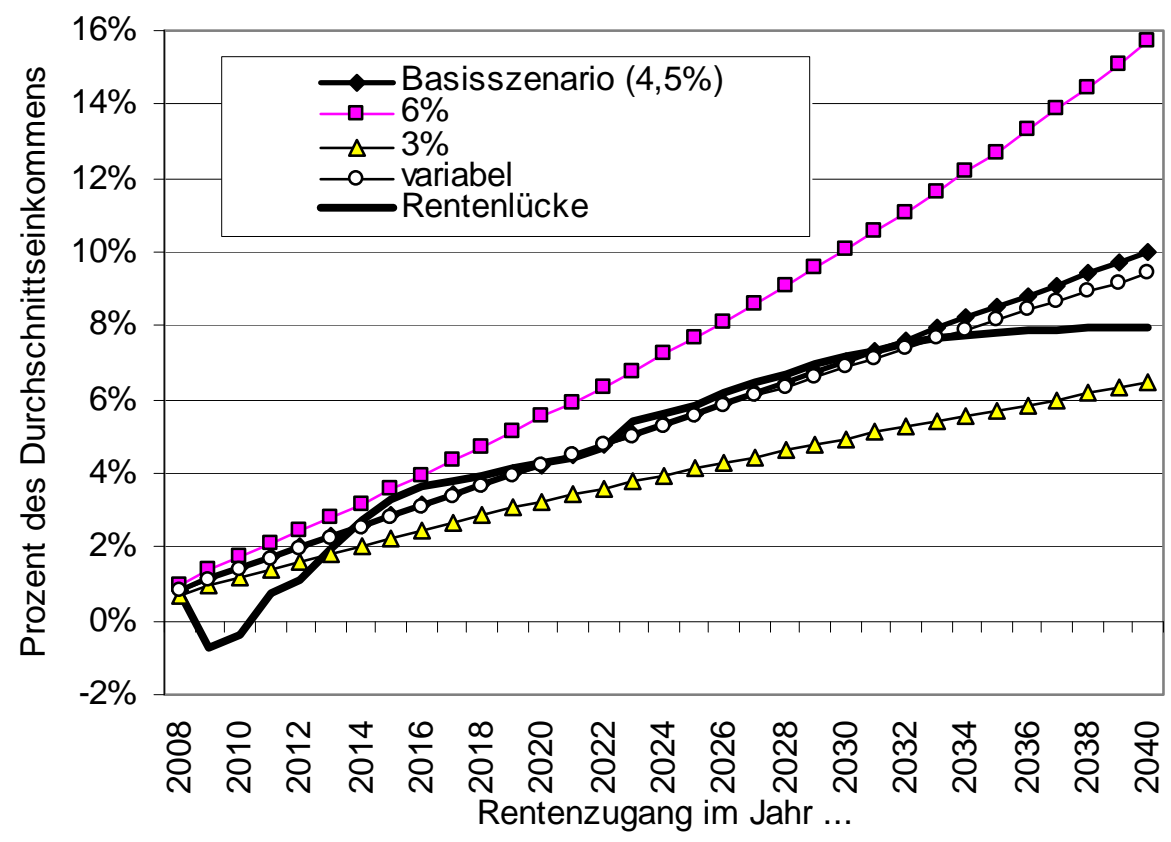

Quelle: eigene Berechnungen.

Abbildung 9: Rentenniveau (GRV+Riester) während der Rentenbezugszeit in Abhängigkeit von der Verzinsung

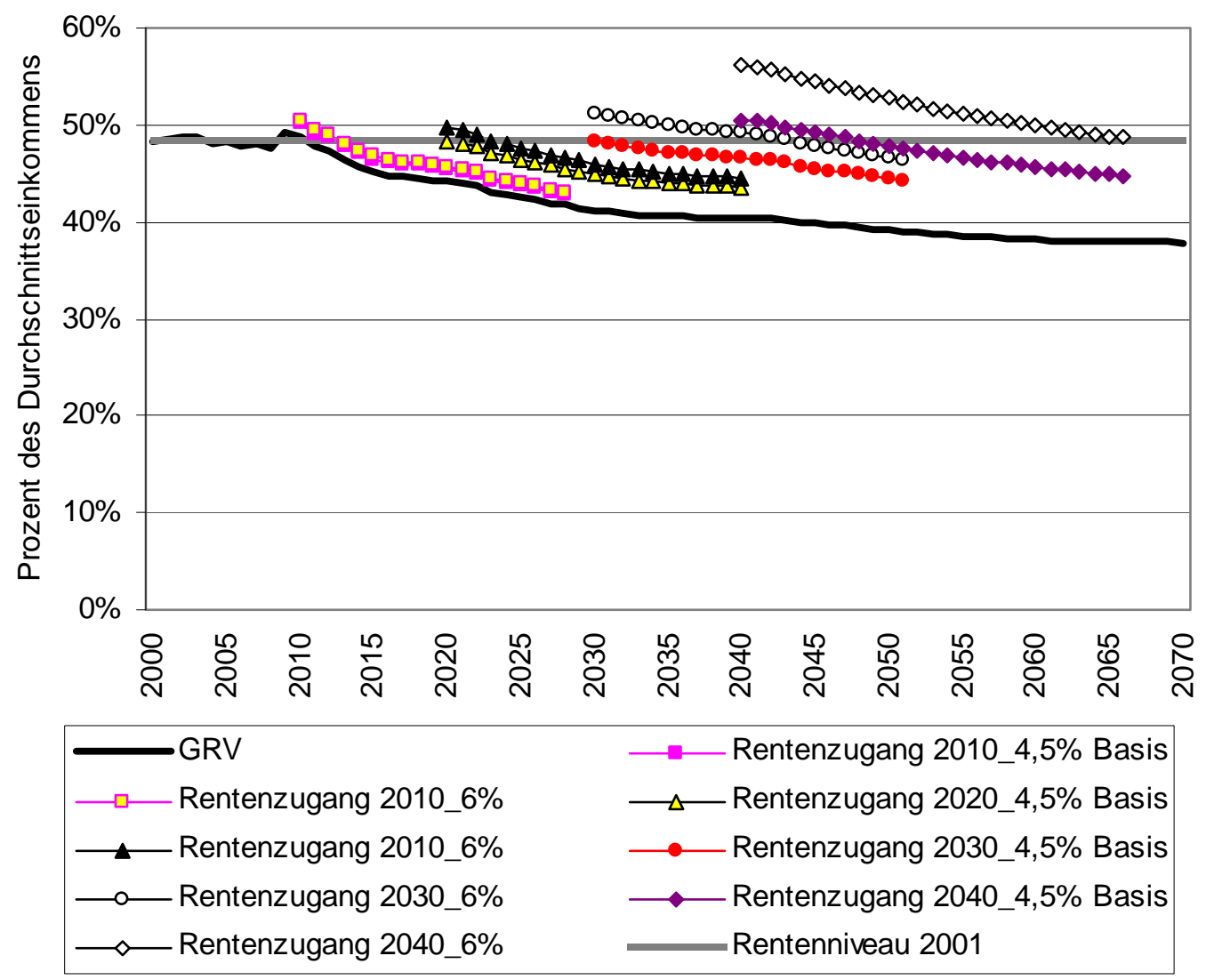

Quelle: eigene Berechnungen. 


\section{Abhängigkeit von der Rentenbezugszeit}

Die Berechnungen werden nun mit alternativen Restlebenserwartungen im Alter von 65 Jahren durchgeführt, um den Einfluss unterschiedlicher Rentenbezugsdauern zu erfassen. Zum einen wird alternativ zur MEA-Projektion die fernere Lebenserwartung eines 65Jährigen herangezogen, wie sie sich aus der Basisannahme des Statistischen Bundesamtes (L1) im Rahmen der 12. Koordinierten Bevölkerungsvorausberechnung ergeben. Zum anderen wird die Variante „Starker Anstieg“ (L2) des Statistischen Bundesamtes verwendet, ${ }^{13}$ die weitgehend mit der MEA-Prognose übereinstimmt (Abbildung 10). Lebensversicherungen verwenden zur Kalkulation der Renten eigene Sterbetafeln (Sterbetafel DAV2004R), die höhere Lebenserwartungen implizieren als diejenigen z.B. des Statistischen Bundesamtes, die für den Durchschnitt der Bevölkerung ermittelt werden. Dies liegt daran, dass die Lebensversicherungen von einem Selektionseffekt ausgehen müssen. So ist zu erwarten, dass Personen, die für sich eine geringe Lebenserwartung vermuten, keine Rentenversicherung abschließen werden. Dagegen werden Personen, die erwarten überdurchschnittlich lange zu leben, eher eine Rentenversicherung kaufen, weil sie für diese Personen eine hohe Rendite bringt. Für die Versicherung bedeutet dies, dass sich „hohe Risiken“ sammeln und sie deshalb von höheren Rentenlaufzeiten, also höheren Lebenserwartungen als für den Durchschnitt der Bevölkerung ausgehen müssen. Diesem Selektionseffekt wird Rechnung getragen, indem aus der von den Versicherungen verwendeten Sterbetafel DAV2004R fernere Lebenserwartungen 65-Jähriger abgeleitet werden. Dazu werden die Sterbewahrscheinlichkeiten der Basissterbetafel im Zeitverlauf reduziert. Für diesen Abschlag wird ein Trend unterstellt. Für die Berechnungen hier wurde der sog. „Trend 1. Ordnung“ verwendet und keine Dämpfung des Trends angenommen, so dass die abgeleiteten Restlebenserwartungen höher ausfallen als mit Dämpfung. ${ }^{14}$ Im Ergebnis sind die im Selektionsszenario unterstellten Restlebenserwartungen 65-Jähriger 4 bis 4,5 Jahre höher als sie vom Statistischen Bundesamt

\footnotetext{
${ }^{13}$ Bei der Variante L1 wird eine Lebenserwartung Neugeborener im Jahr 2060 von 85,0 Jahren (männlich) und 89,2 Jahren (weiblich) und bei der Variante L2 von 87,7 Jahren (männlich) und 91,2 Jahren (weiblich) unterstellt. Vgl. Statistisches Bundesamt (2009), S. 37.

${ }^{14}$ Die Dämpfung soll einen allmählichen Übergang vom zunächst unterstellten Starttrend (Trend 2. Ordnung) auf den niedriger liegenden Zieltrend bewirken. Je nachdem wann mit der Dämpfung des Trends begonnen wird und wie lange die Dämpfung andauert, wie schnell also der niedrigere Zieltrend erreicht wird, ergeben sich unterschiedliche Ergebnisse. Ein Beginn der Dämpfung nach 5 Jahren und eine Dämpfungsdauer von 5 Jahren ergibt im Jahr 2050 eine um knapp 3 Jahre niedrigere Restlebenserwartung als hier im Selektionsszenario unterstellt wurde. Eine nach 15 Jahren beginnende und 25 Jahre andauernde Dämpfung bedeutet, dass der niedrigere Zieltrend erst später erreicht wird. Entsprechend sind die Restlebenserwartungen im Jahr 2050 nur um rund 2 Jahre geringer als im Selektionsszenario. Zur Berechnung der Versicherungssterbetafeln vgl. die Erläuterungen der DAV zur Herleitung der Sterbetafeln für Rentenversicherungen.
} 
in der Variante L2 berechnet werden. ${ }^{15} \mathrm{Zu}$ berücksichtigen ist allerdings, dass die RiesterRente grundsätzlich für alle gedacht ist, die in der gesetzlichen Rente aufgrund der Reformen eine Reduktion des Rentenniveaus hinnehmen müssen. Entsprechend dürften diese Selektionseffekte bei der Riester-Rente eine geringere Rolle spielen.

\section{Abbildung 10: Alternative Annahmen zur ferneren Lebenserwartung 65-jähriger Personen}

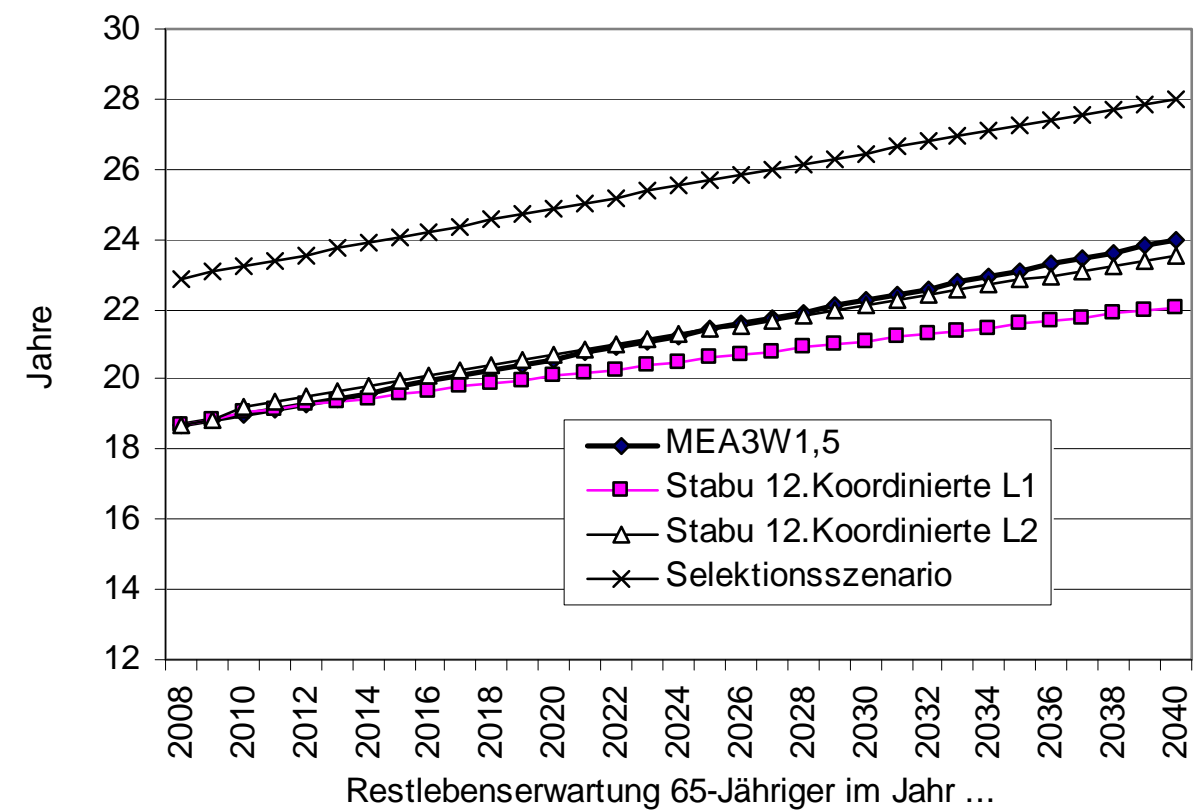

Quelle: eigene Berechnungen.

Eine höhere Lebenserwartung impliziert einen längeren Rentenbezug. Das gesparte RiesterKapital muss also auf eine längere Zeit verteilt werden. Deshalb bedeutet eine höhere Lebenserwartung durchweg niedrigere Rentenzahlungen. Es zeigt sich aber, dass der Einfluss der Lebenserwartung auf das Riester-Rentenniveau relativ gering ist.

Ein Jahr längere Rentenlaufzeit muss also mit einem über die gesamte Rentenlaufzeit geringeren Rentenzahlbetrag „finanziert“ werden. Der Zahlungsstrom dieser Abschläge muss aufgezinst bis zum Ende der Rentenphase mit dem Rentenbetrag übereinstimmen, der für das zusätzliche Rentenjahr benötigt wird. Da dieser geringere Rentenzahlbetrag so über die

\footnotetext{
${ }^{15}$ Die Rentenlücke variiert ebenfalls mit der unterstellten Lebenserwartung. Zur Berechnung der Rentenlücke wurde die Lebenserwartung im Basisszenario unterstellt. Würde man die geringere Lebenserwartung der Variante L1 des Statistischen Bundesamtes unterstellen, würde die Lücke etwas geringer ausfallen. Denn der Rentnerquotient würde tendenziell weniger stark steigen und die Rentenanpassungen würden etwas höher ausfallen. Die Verwendung der Lebenserwartung im Selektionsszenario ist hingegen für die Berechnung der Rentenlücke nicht sinnvoll, weil es in der gesetzlichen Rentenversicherung keine solchen Selektionseffekte gibt. Somit ist die durchschnittliche Lebenserwartung für die Projektionen in der gesetzlichen Rentenversicherung relevant.
} 
gesamte Rentenlaufzeit „angespart“ und verzinst wird, ist anfänglich nur ein geringer Abschlag notwendig. Zum Beispiel führt ein um 100 Euro jährlich geringerer Rentenzahlbetrag mit 4,5\% verzinst nach 20 Jahren zu einem Betrag von über 3.000 Euro, mit dem dann ein Jahr längerer Rentenbezug finanziert werden kann. Auch im Selektionsszenario mit einer um rund 4 bis 4,5 Jahre höheren Lebenserwartung als in der Version L2 des Statistischen Bundesamts kann der weitaus größte Teil der Rentenniveaulücke bei Rentenzugang gedeckt werden (Abbildung 11).

Da die hier berechneten Riester-Rentenniveaus nicht sehr stark vom Basisszenario abweichen, gelten bei Anwendung der strengen Zieldefinition die gleichen Aussagen wie für das Basisszenario.

Abbildung 11: Rentenlücke und Riester-Rentenniveau in Abhängigkeit von der Lebenserwartung

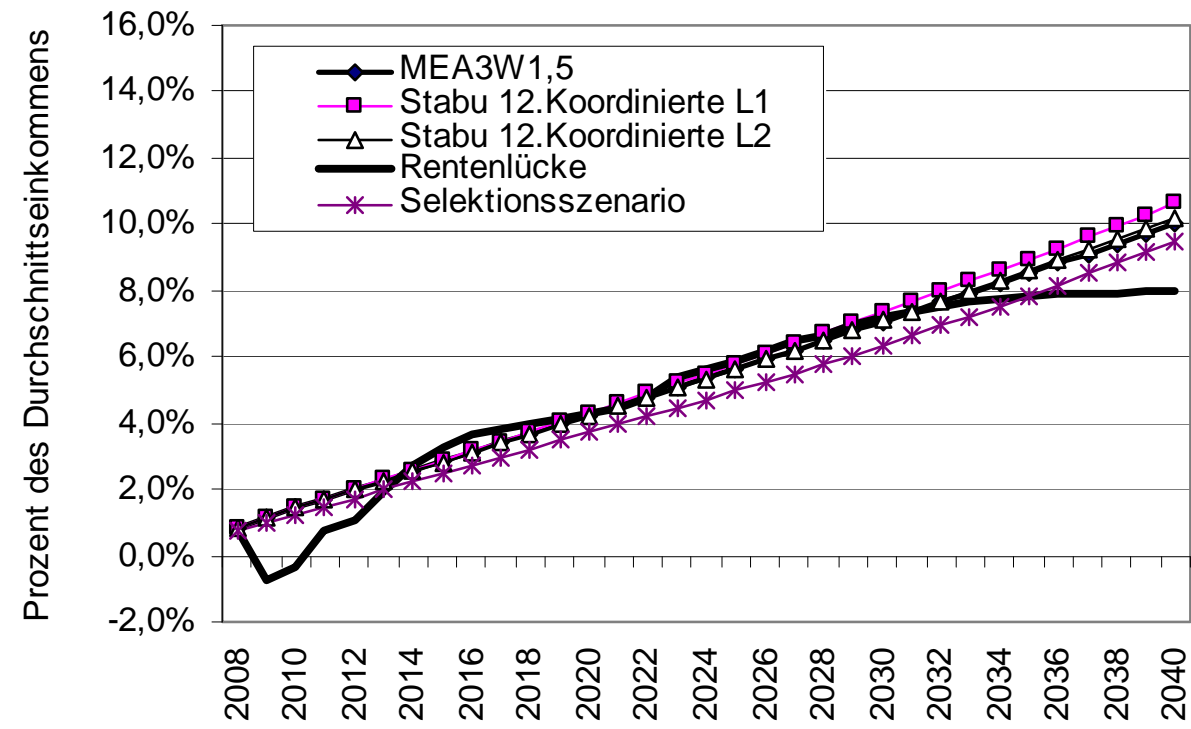

Rentenzugang im Jahr ...

Quelle: eigene Berechnungen.

\section{Abhängigkeit von der Dynamisierung der Riester-Rente}

Ob die Riester-Rente die Rentenlücke beim Rentenzugang decken kann, hängt auch davon ab, wie sich die Riester-Rente im Zeitverlauf entwickelt. Letztlich ist es die Frage danach, wie das gesparte Kapital auf die Rentenlaufzeit aufgeteilt wird. Unterstellt man einen im Zeitverlauf steigenden Rentenbetrag, ist die Rente zu Beginn der Rentenphase niedriger als im Falle eines im Zeitverlauf konstanten Rentenzahlbetrags, also im Falle einer Dynamisierung von null. In diesem Fall nimmt allerdings der Realwert der Rente mit der Zeit ab. Im Basisszenario wurde eine konstante Dynamisierungsrate von 1,5\% p.a. angenommen. 
Alternativ dazu wird die Riester-Rente für den Fall berechnet, dass die Rente konstant bleibt (0\% Dynamisierung), dass sie mit einer Rate von 3\% p.a. steigt und dass sie sich variabel mit der Rentenanpassungsrate der gesetzlichen Rente erhöht (Abbildung 12). ${ }^{16}$

Wird auf eine Dynamisierung der Riester-Rente verzichtet, ist das Niveau der Riester-Rente bei Rentenzugang entsprechend hoch und die Rentenlücke beim Rentenzugang kann mehr als geschlossen werden (Abbildung 13). Das Gesamtversorgungsniveau ist höher als im Basisszenario. Im Zeitverlauf nimmt das Riester-Rentenniveau während der Rentenbezugszeit jedoch ab, weil die Riester-Rente nominal konstant bleibt, das Lohneinkommen aber steigt. Das Gesamtversorgungsniveau sinkt während der Rentenbezugszeit schneller als im Basisszenario (Abbildung 14).

Unterstellt man dagegen eine Dynamisierung von 3\%, dann kann die Rentenlücke bei Rentenzugang nicht vollständig beseitigt werden (Abbildung 13). Dafür sinkt das Gesamtrentenniveau im Zeitverlauf aber nicht so stark ab (Abbildung 14). Dynamisiert man die Riester-Rente variabel und in der Höhe genauso wie die gesetzliche Rente, kann die Rentenlücke im Rentenzugangsjahr ebenfalls nur annähernd geschlossen werden. Eine dramatische Unterdeckung ist aber nicht festzustellen. Während der Rentenbezugszeit reduziert sich das Rentenniveau parallel zum Rentenniveau der gesetzlichen Rente.

Soll die Rentenniveaulücke nicht nur beim Rentenzugang, sondern über die gesamte Rentenbezugszeit geschlossen werden, ist - wie aus Gleichung (11) abgeleitet werden kann eine höhere Dynamisierung erforderlich, als in den hier unterstellten Szenarien: Die Dynamisierungsrate müsste der Lohnzuwachsrate zuzüglich der Wachstumsrate der Rentenniveaulücke $R N L$ entsprechen.

\footnotetext{
${ }^{16}$ Die Rentenanpassungsraten werden Gasche (2010) entnommen.
} 
Abbildung 12: Alternative Dynamisierungsraten der Riester-Rente

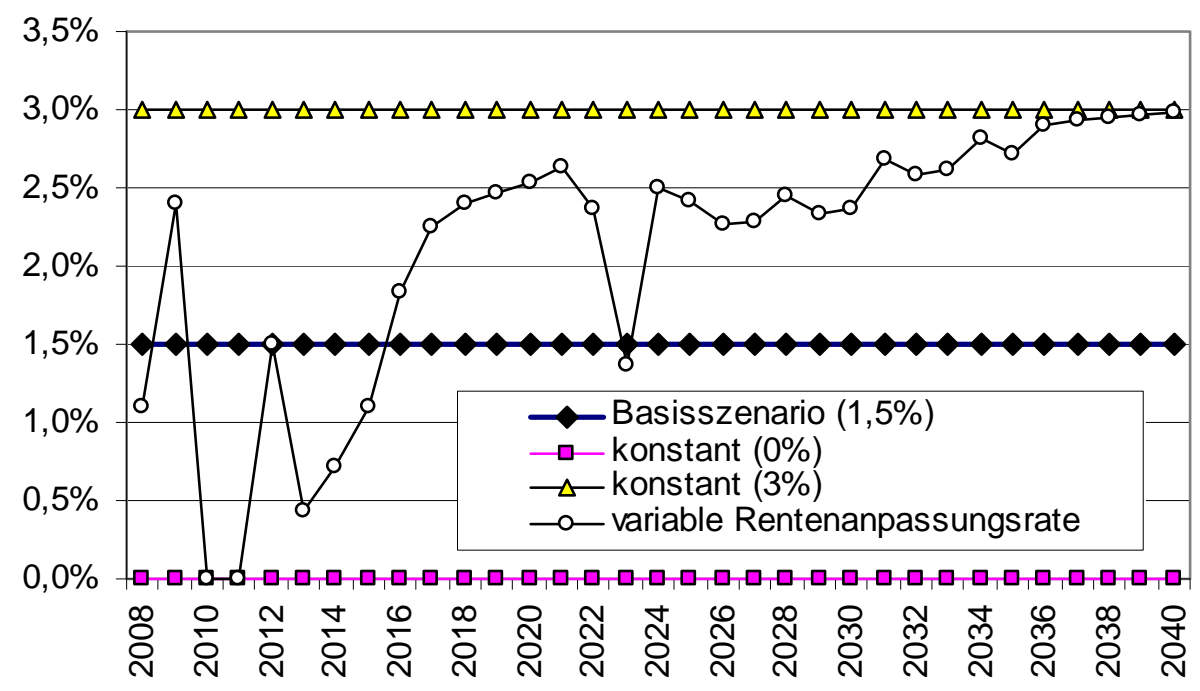

Quelle: eigene Berechnungen

Abbildung 13: Rentenlücke und Riester-Rentenniveau in Abhängigkeit von der Dynamisierungsrate

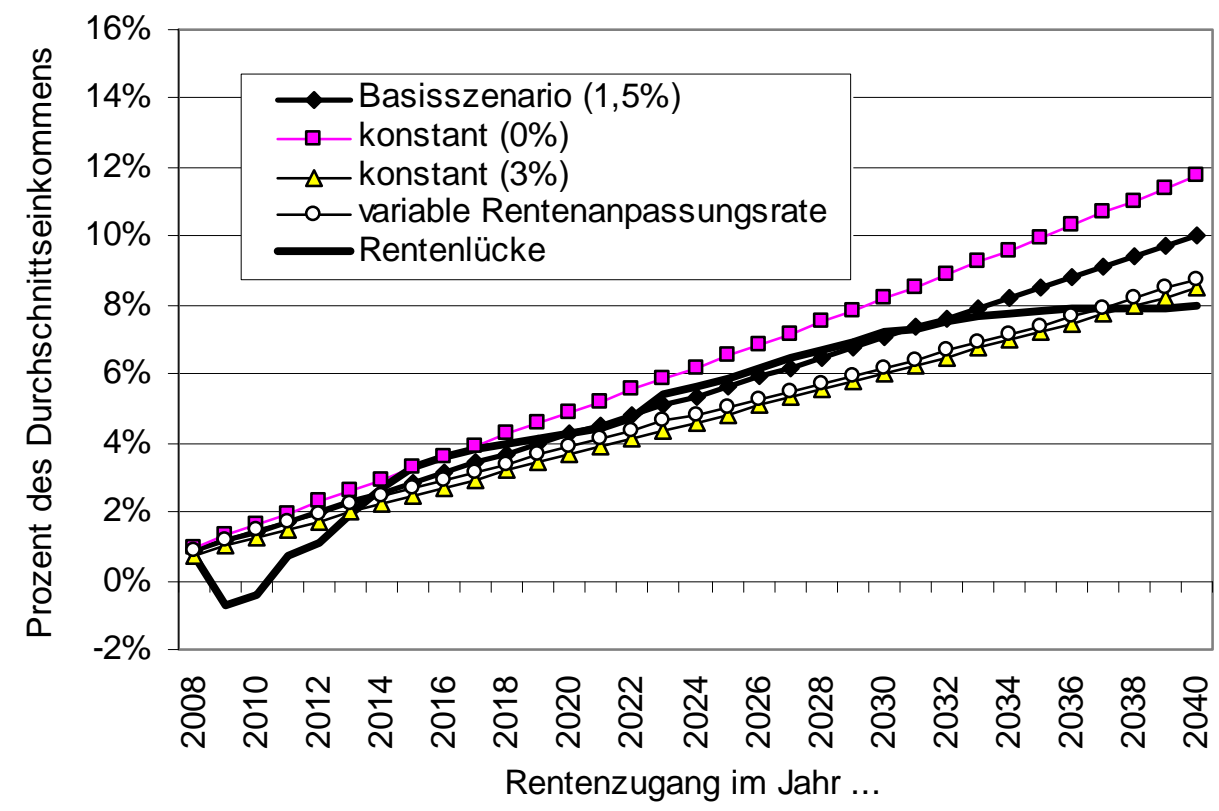

Quelle: eigene Berechnungen 


\section{Abbildung 14: Riester-Rentenniveau in der Rentenbezugszeit in Abhängigkeit von der Dynamisierungsrate}

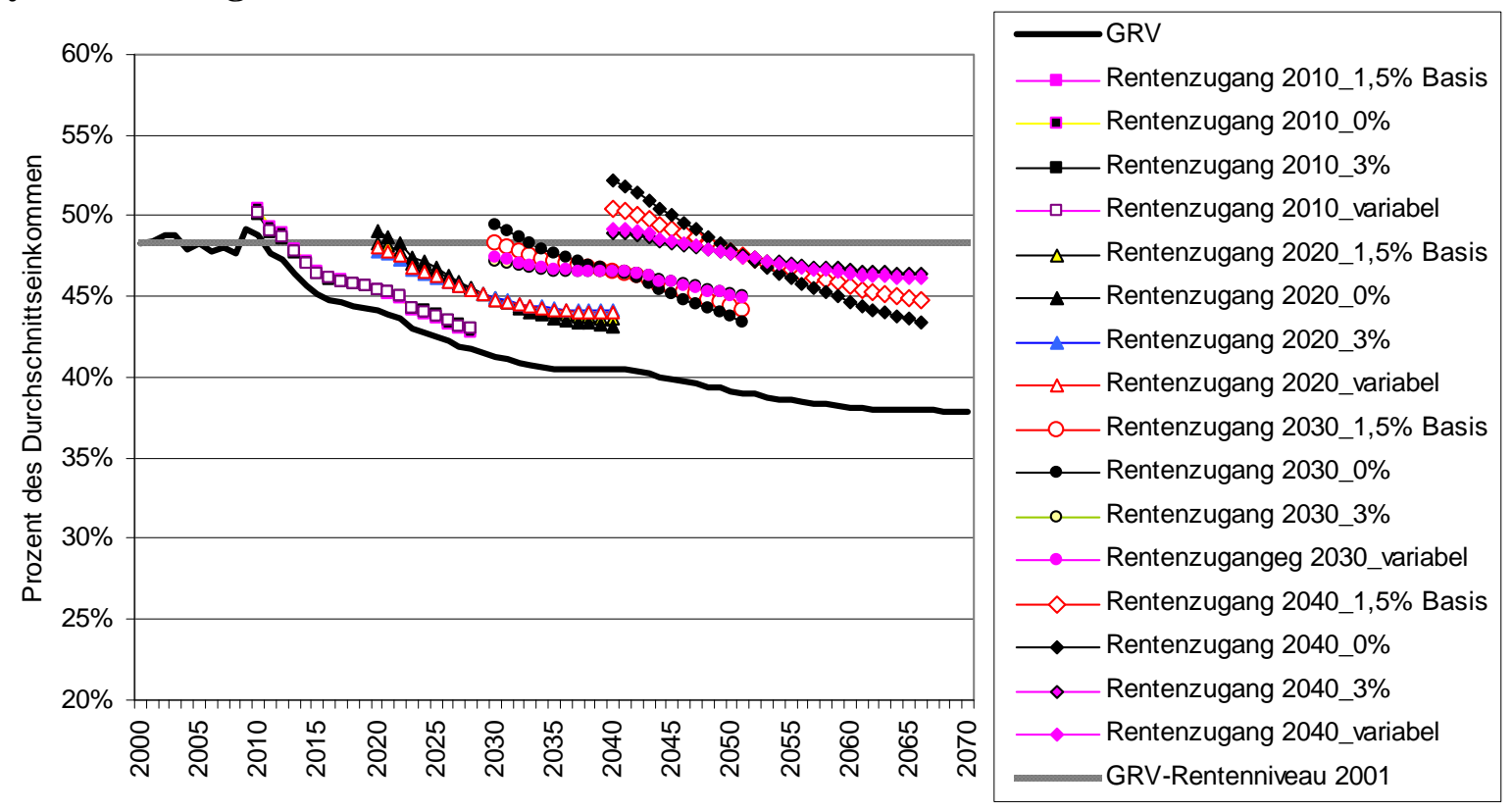

Quelle: eigene Berechnungen

\section{Abhängigkeit vom Riester-Beitragssatz}

Bisher wurde das Riester-Rentenniveau unter der Annahme betrachtet, dass immer der Riester-Beitragssatz zur Erlangung der maximalen Förderung geleistet wurde. Tatsächlich zahlen nicht alle Riester-Sparer den vollen Satz. Deshalb wird in Alternativrechnungen angenommen, dass ab 2008 nicht 4\% des Bruttoeinkommens wie im Basisszenario, sondern nur 2\% bzw. 3\% gezahlt werden. Zum Vergleich wird ein Szenario betrachtet, in dem ab 2015 der Satz auf 6\% erhöht wird und auch voll ausgeschöpft wird (Abbildung 15). ${ }^{17}$

Es zeigt sich somit, dass der Riester-Beitragssatz von 4\% bei einfacher Zieldefinition knapp, aber ausreichend bemessen ist (Abbildung 16). Schon ein Satz von 3\% des Bruttoeinkommens könnte die Rentenlücke nicht decken. Zahlt man nur den halben Satz, also ab 2008 2\% des Bruttoeinkommens, kann man die Lücke bei Rentenzugang nur zur Hälfte bis zwei Drittel schließen. Ein Riester-Beitragssatz von 6\% ab 2015, könnte ab 2030 ein Riester-Renteniveau von über $8 \%$ erzeugen.

Das strenge Ziel, die Rentenlücke über die gesamte Rentenbezugszeit zu schließen, kann nur für den Fall erreicht werden, dass der Riester-Beitragssatz 6\% beträgt.

\footnotetext{
${ }^{17}$ Der maximal förderfähige Sparbetrag müsste ebenfalls entsprechend angepasst werden.
} 
Abbildung 15: Alternative „Riester-Beitragssätze“

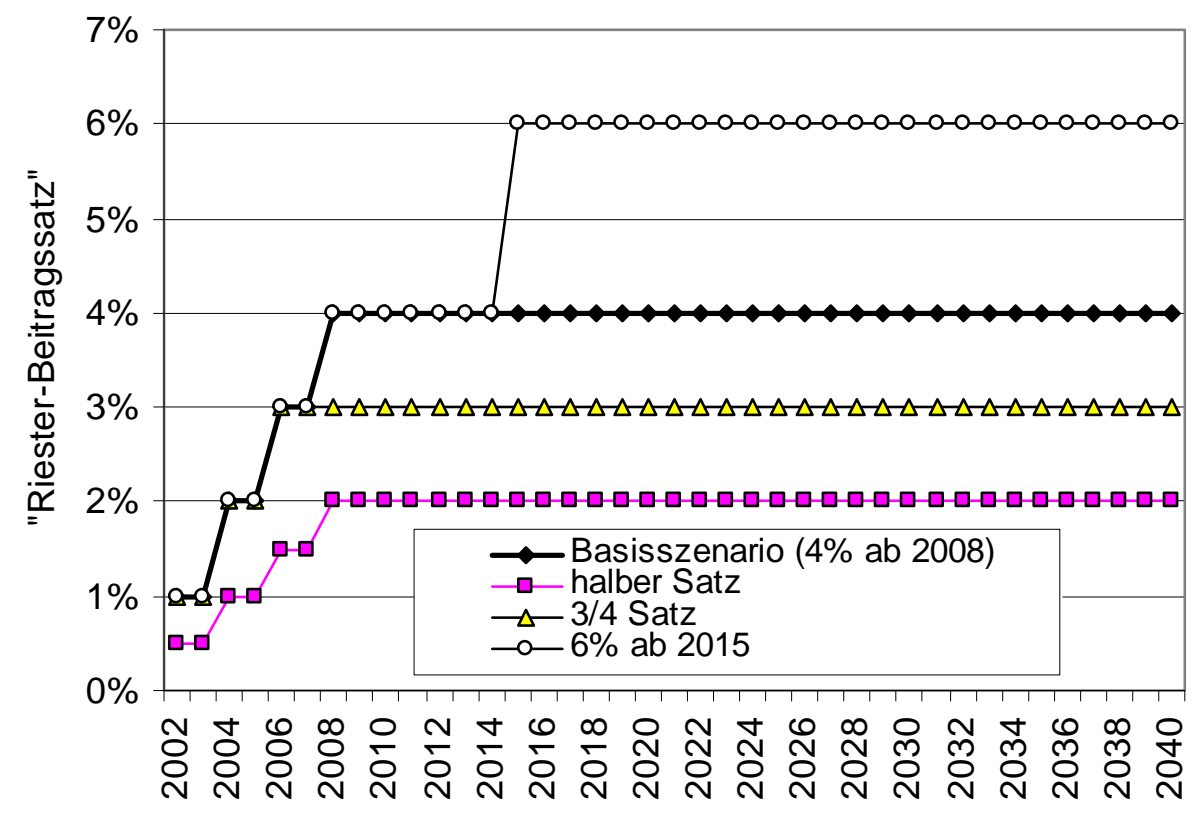

Quelle: eigene Berechnungen

Abbildung 16: Rentenlücke und Riester-Rentenniveau in Abhängigkeit vom „RiesterBeitragssatz“"

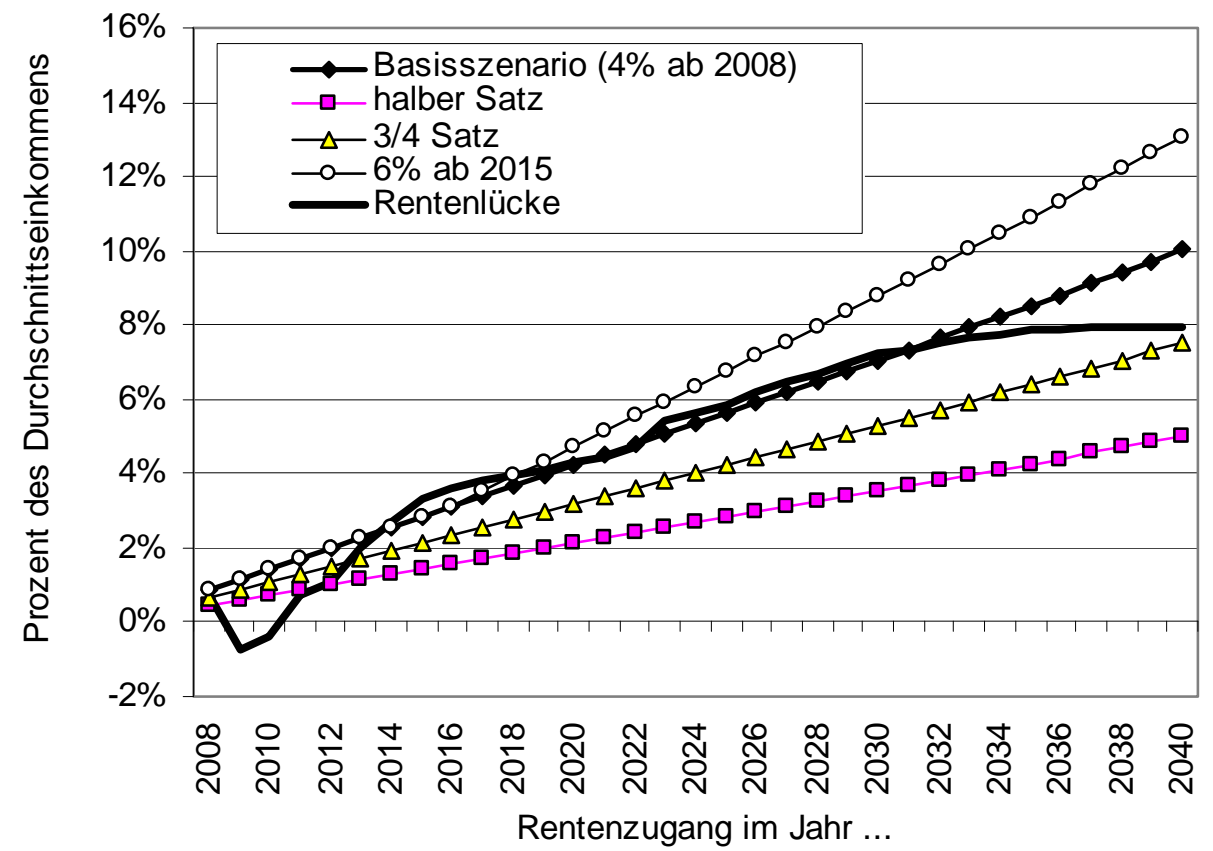

Quelle: eigene Berechnungen

\section{Abhängigkeit von der Ansparzeit}

Im Basisszenario wurde angenommen, dass jeder Riester-Sparer bereits im Jahr 2002 mit dem Sparen beginnt, so dass beispielsweise jemand, der im Jahr 2040 in Rente geht, 38 Jahre in 
den Riester-Vertrag einzahlt. Diese Annahme wird nun gelockert, indem unterstellt wird, dass maximal 10, 20 bzw. 30 Jahre vor dem Rentenzugangsjahr mit dem Sparen begonnen wurde (Abbildung 17).

Die Simulationsergebnisse zeigen, dass der Ansparzeit eine enorme Bedeutung zukommt. Spart man nur 10 Jahre vor dem Rentenzugang, dann kann man mit der Riester-Rente ein Rentenniveau von kaum mehr als 2\% erzielen. Bei 20 Jahren Ansparzeit vor Rentenzugang sind es 5\%. Nur wenn man 30 Jahre spart, kann man die Lücke bei Rentenzugang ausgleichen (Abbildung 18). ${ }^{18}$ Bei Anwendung der strengen Zieldefinition reicht auch diese Ansparzeit nicht aus.

\section{Abbildung 17: Alternative Ansparzeiten vor dem Rentenzugangsjahr}

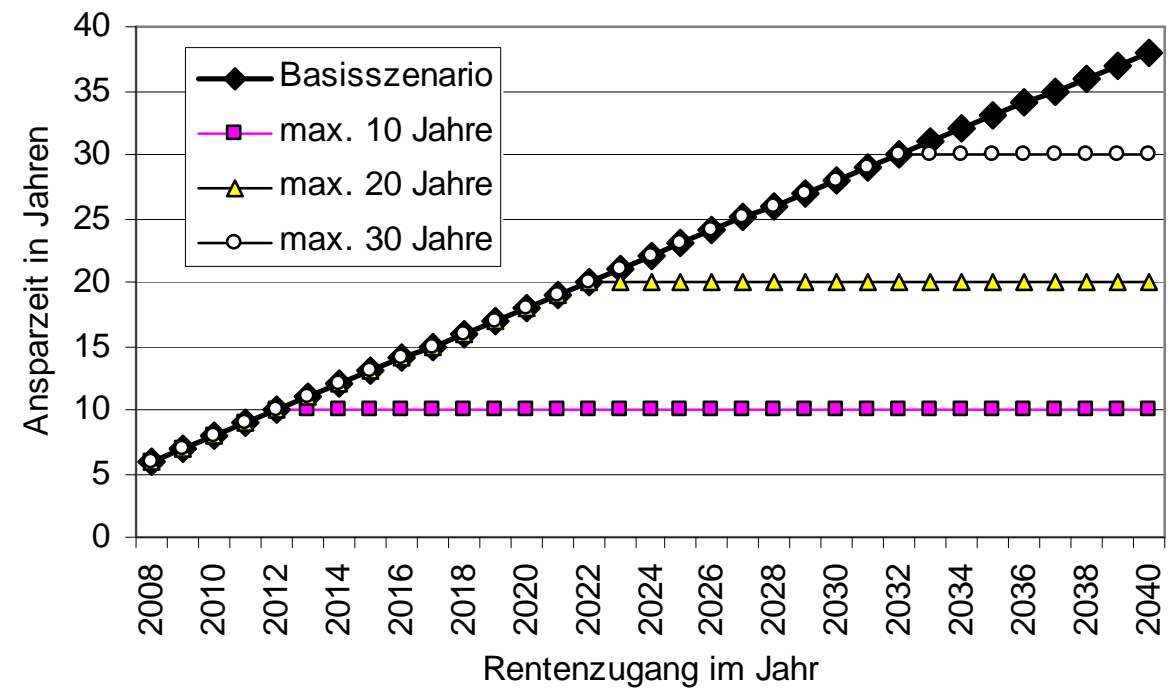

Quelle: eigene Berechnungen

\footnotetext{
${ }^{18}$ Siehe auch Essig und Reil-Held (2003) für Simulationen über die Auswirkungen unterschiedlicher Lohnprofile und das Aussetzen der Riester-Sparbeträge für bestimmte Zeiträume sowie Gasche (2008).
} 


\section{Abbildung 18: Riester-Rentenniveau in Abhängigkeit von der Ansparzeit}

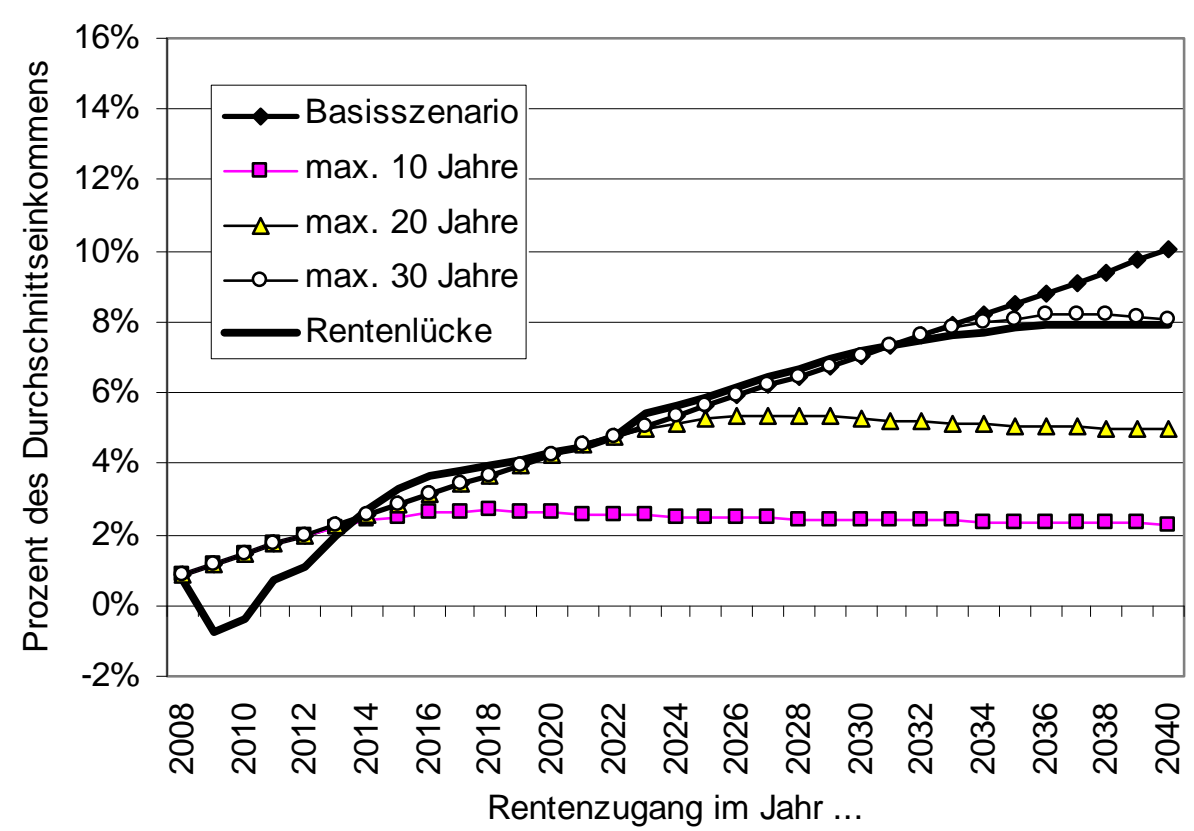

Quelle: eigene Berechnungen

\section{Abhängigkeit vom Einkommensprofil}

In Abschnitt 2 wurde gezeigt, dass die Rentenlücke unabhängig von individuellen Größen wie dem Einkommen ist. Die Höhe der Riester-Rente dagegen hängt vom individuellen Einkommen bzw. von der Entwicklung des Einkommens im Zeitverlauf ab, da der RiesterBeitrag einen Prozentsatz des Einkommens ausmacht. Bisher wurde ein Standardrentner unterstellt, der im jeden Jahr das Durchschnittseinkommen verdient. Das Einkommensprofil ausgedrückt in pro Jahr erworbenen Entgeltpunkten verläuft also flach. In jedem Jahr erwirbt der Durchschnittseinkommensbezieher einen Entgeltpunkt (Abbildung 19). In der Realität beobachtet man dagegen mit dem Alter - auch relativ zum Durchschnittseinkommen steigende Einkommensprofile. Betrachtet werden nun beispielhaft verschiedene altersspezifische Einkommensprofile, die alle über das Alter von 20 Jahren bis 65 Jahren zu 45 Entgeltpunkten führen. Beim Standardfall des Durchschnittseinkommensbeziehers ist der Erwerb der Entgeltpunkte gleichmäßig verteilt. Im Gegensatz dazu wird ein Fall betrachtet, in dem in jungen Jahren mit einem unterdurchschnittlichen Einkommen begonnen wird, das aber dann mit zunehmendem Alter relativ zum Durchschnittseinkommen ansteigt. Verwendet wird hier das altersspezifische Einkommensprofil, das sich ergibt, wenn man die altersspezifischen Durchschnittseinkommen der sozialversicherungspflichtig Beschäftigten eines Jahres im 
Querschnitt betrachtet. ${ }^{19}$ Zum Vergleich wird ein stilisiertes Profil betrachtet, bei dem erst ab dem Alter von 28 Jahren Einkommen erzielt wird. Dieses Einkommen steigt dann aber relativ zum Durchschnittseinkommen an. Dieses Profil entspricht qualitativ dem eines Akademikers, der aufgrund seiner langen Ausbildungszeit erst später ins Erwerbsleben eintritt, dann aber ein überdurchschnittliches Einkommen erzielt.

\section{Abbildung 19: Alternative Einkommensprofile ${ }^{20}$}

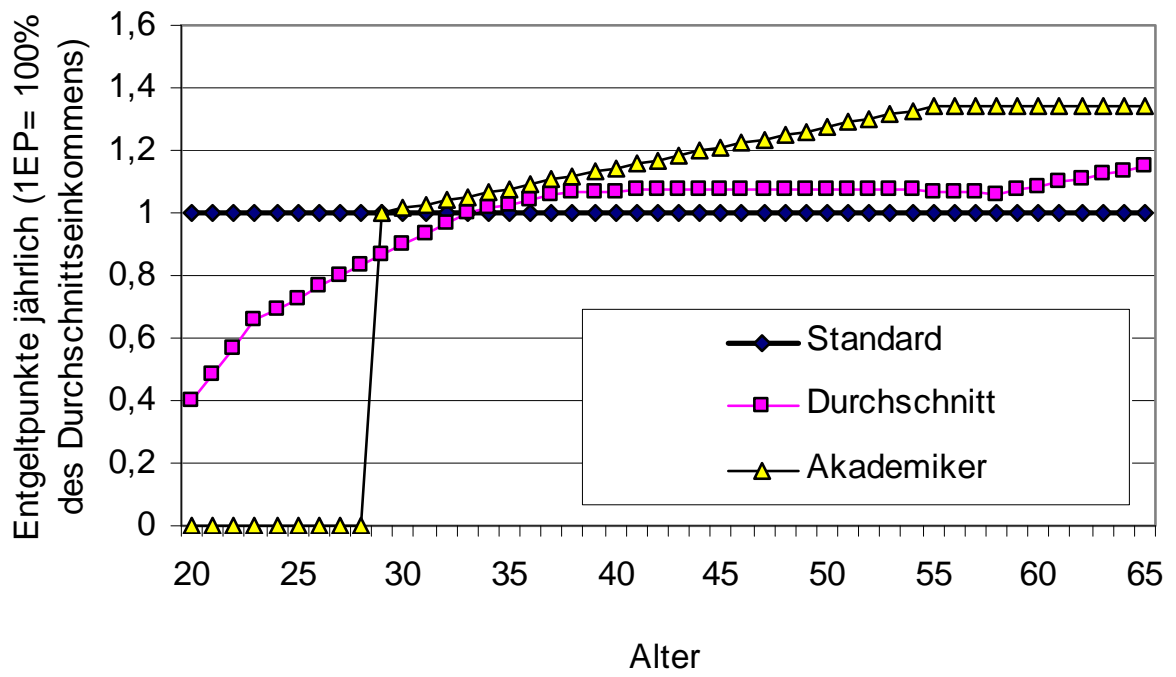

Quelle: eigene Berechnungen

Ein ansteigendes Einkommensprofil bedeutet, dass die Riester-Sparbeträge mit dem Alter relativ zunehmen. Die weit zurückliegenden Sparbeiträge, bei denen sich der Zinseszins besonders bemerkbar macht, sind aber niedriger. Dies führt für sich genommen dazu, dass ein steigendes Einkommensprofil bei gleicher Entgeltpunktzahl im Vergleich zum Standardprofil eine geringere Riester-Rente erzeugt. Dem entgegengesetzt wirkt die Tatsache, dass mit höherem Einkommen ein größerer Betrag in den Riester-Vertrag eingezahlt werden kann. Der Verzicht auf Einkommen in jungen Jahren und damit auch auf Riester-Sparbeträge wird gleichsam in ein höheres Einkommen im Alter „investiert“, aus dem dann mehr gespart werden kann. Je nachdem, ob sich das Sparkapital oder das individuelle Einkommen, also das Humankapital, besser verzinst, ergibt sich mit steigendem Einkommensprofil eine niedrigere oder höhere Riester-Rente. Bei der hier gewählten Annahmenkombination ist das RiesterRenteniveau höher, wenn später im Leben mehr gespart wird: Die steigenden Einkommensprofile des Akademikers und des Durchschnitts aller Versicherten erzielen ein

\footnotetext{
${ }^{19}$ Vgl. Gasche (2009).

${ }^{20}$ Alle Einkommensprofile führen zu 45 Entgeltpunkten.
} 
höheres Riester-Rentenniveau als der Durchschnittseinkommensbezieher mit dem konstanten Einkommensprofil (Abbildung 20). ${ }^{21}$

Ein Vergleich der Effekte der unterschiedlichen Einkommensprofile ist erst dann aussagekräftig, wenn ein gesamtes Erwerbsleben, betrachtet wird. Hier ist dies erst ab dem Jahr 2047 möglich. In den Rentenzugangsjahren vor 2047 ist das Riester-Renteniveau beispielsweise des Akademikers vor allem deshalb höher als das des Durchschnittseinkommensbeziehers, weil der Akademiker im höheren Alter aufgrund seines höheren Einkommens mehr spart als der Durchschnittseinkommensbezieher. Zum Beispiel ist ein Akademiker mit dem Rentenzugangsjahr 2010 im Jahr 2002, wenn er mit dem RiesterSparen beginnt 57 Jahre alt und hat ein überdurchschnittliches Einkommen, kann also bis zum Rentenzugang 2010 mehr sparen als der Durchschnittseinkommensbezieher gleichen Alters. Entsprechend erzielt er eine höhere Riester-Rente und das Rentenniveau ist höher.

\section{Abbildung 20: Rentenlücke und Riester-Rentenniveau in Abhängigkeit vom Einkommensprofil ${ }^{22}$}

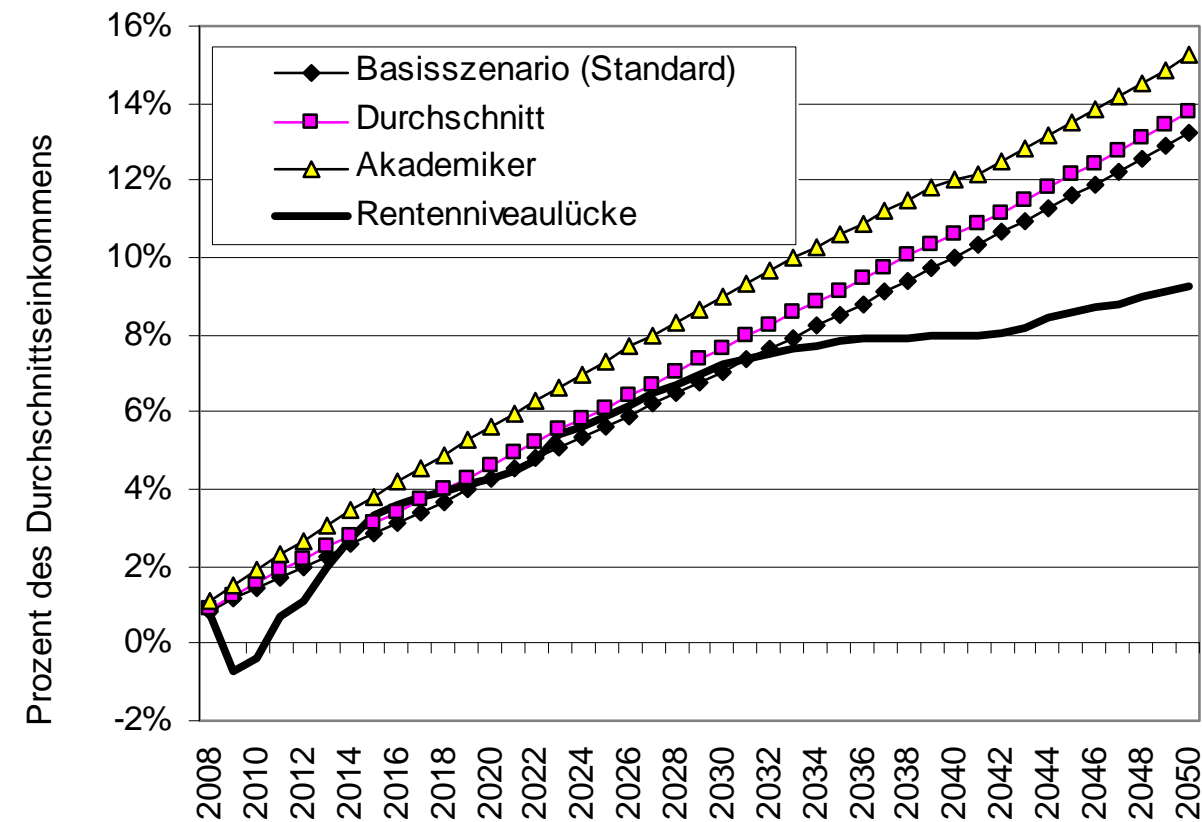

Rentenzugang im Jahr ...

Quelle: eigene Berechnungen

\footnotetext{
${ }^{21}$ Allerdings muss dies nicht immer so sein. So kann man Einkommensprofile konstruieren, bei denen der Zinseszinseffekt der frühen Ersparnis den Vorteil der höheren Ersparnis in späteren Jahren überwiegt und das Rentenniveau im Standardfall höher ist.

${ }^{22}$ Rentenabschläge im Fall des Akademikers, der keine 45 Beitragsjahre ausweist, wurden außer Acht gelassen.
} 
Die Aussage über die Fähigkeit der Riester-Rente, die Rentenlücke zu schließen, ist zudem unabhängig von der absoluten Einkommenshöhe. Betrachtet man beispielsweise einen Niedrigeinkommensbezieher, der in seiner Erwerbszeit immer nur die Hälfte des Durchschnittseinkommens bezieht, dann ist die Rentenniveaulücke ausgedrückt als Prozentsatz des Durchschnittseinkommens nur halb so groß wie die des Durchschnittseinkommensbeziehers. Das Riester-Rentenniveau beträgt ebenfalls die Hälfte, so dass man hinsichtlich der Frage, ob die Rentenlücke durch die Riester-Rente geschlossen wird, zum gleichen Ergebnis kommt.

\section{Abhängigkeit von den Kosten}

Im Basisszenario wurde übereinstimmend mit den Annahmen der Rürup-Kommission ${ }^{23}$ und der Annahme für Berechnungen des Gesamtversorgungsniveaus im Rentenversicherungsbericht ${ }^{24}$ Kosten in Höhe von $10 \%$ des Sparbetrages angenommen. Tatsächlich sind die Kostenstrukturen der Riester-Verträge sehr unterschiedlich. Sie beziehen sich sowohl auf die Ansparphase und die Rentenphase, haben verschiedene Berechnungsgrundlagen und werden unterschiedlich über die Zeit verteilt, so dass eine repräsentative Kostenerfassung schwer ist. ${ }^{25}$ Um eine möglichst weite Bandbreite zu erfassen werden nun die Riester-Rentenniveaus für den Fall ohne Kosten sowie für Kosten in Höhe von 20\% bzw. 30\% des Sparbetrages berechnet. Der letztgenannte Fall stellt ein Extremszenario dar. Zudem wird der Fall betrachtet, dass die Kosten die Verzinsung des Riester-Produkts um ein Fünftel schmälern. Der Zinssatz beträgt also nicht 4,5\%, sondern 3,6\%. p.a. Es zeigt sich dass auch bei einer Erhöhung der Kosten auf 20\% des Sparbetrages die Lücke bei Renteneintritt noch weitgehend geschlossen wird. Bei 30\% Kosten können dagegen bis 2030 nur 76\% bis 87\% der Lücke geschlossen werden. Machen die Kosten 20\% der Rendite aus, entspricht dies in etwa dem Fall, in dem als Kosten 20\% des Sparbetrags veranschlagt werden (Abbildung 21).

\footnotetext{
${ }^{23}$ Vgl. Rürup-Kommission (2003), S. 108, Tabelle 3-11.

${ }^{24}$ Vgl. BMAS (2009), Übersicht B8.

${ }^{25}$ Vgl. zu den Kosten von Riester-Verträgen z.B. Oehler (2009).
} 
Abbildung 21: Rentenlücke und Riester-Rentenniveau in Abhängigkeit von den Kosten

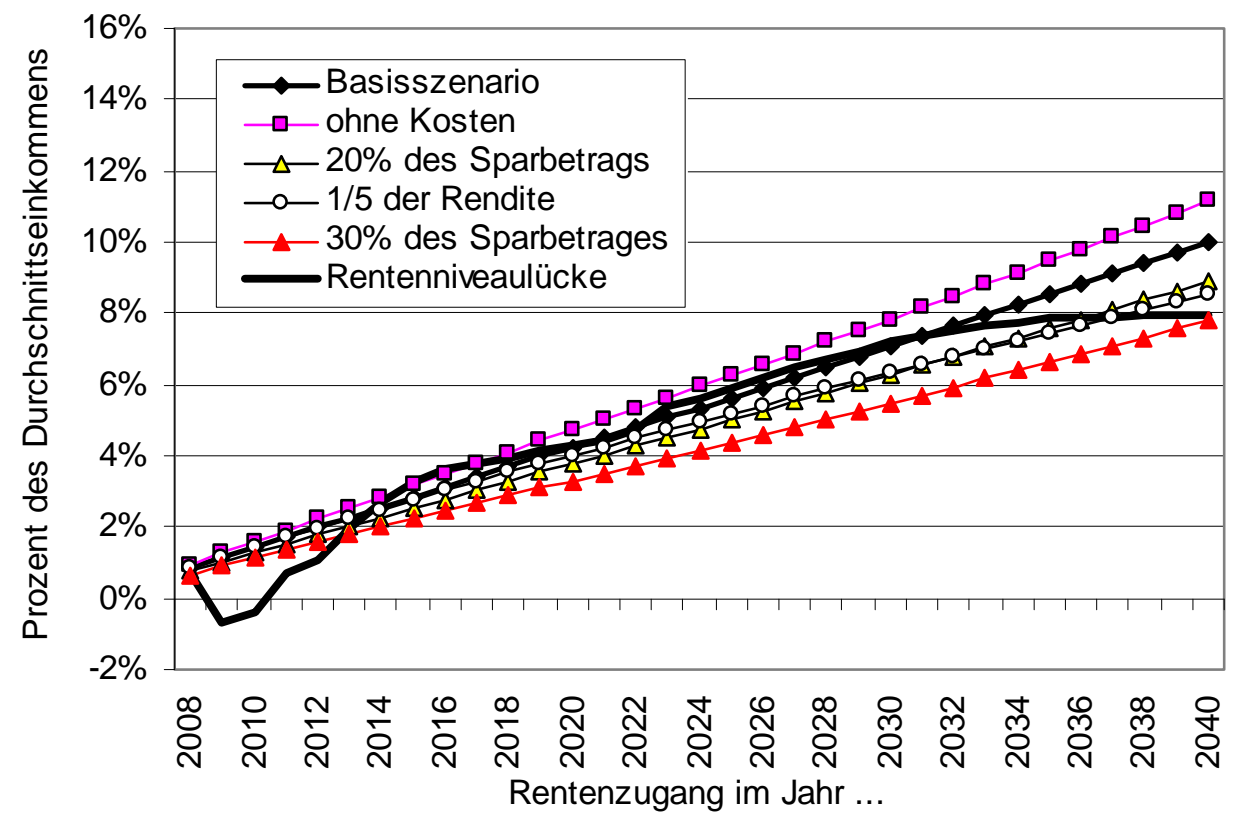

Quelle: eigene Berechnungen

\section{Abhängigkeit von der unterstellten Lohnzuwachsrate}

Oben wurde gezeigt, dass die Rentenlücke und die Rentenniveaulücke nicht von der Lohnwachstumsrate abhängen, sondern vom Verhältnis der Lohnzuwachsrate zur Rentenanpassungsrate und damit vom Nachhaltigkeitsfaktor und vom Riester-Faktor (Gleichung 4). Allerdings ist die unterstellte Lohnzuwachsrate für die Frage, ob die RiesterRente die Lücke schließen kann, von entscheidender Bedeutung. Ein geringerer Lohnzuwachs führt zu einem geringeren Lohnniveau, so dass eine gegebene Riester-Rente bezogen auf dieses Lohnniveau einen größeren Anteil ausmacht, ${ }^{26}$ die Rentenniveaulücke also eher geschlossen wird. Im Folgenden wird deshalb die Lohnzuwachsrate variiert. Im Basisszenario wurden die Lohnannahmen des Rentenversicherungsberichts verwendet, der langfristig von einer Zuwachsrate von 3\% p.a. ausgeht. Diese Annahme ist sicherlich recht optimistisch. Deshalb werden in zwei Alternativszenarien eine langfristige Lohnzuwachsrate von 2,25\% (Annahme der Rürup-Kommission) bzw. 1,5\% betrachtet.

Die Rentenlücken unterscheiden sich zunächst deutlich, da es bei geringeren Lohnerhöhungen länger dauert, bis der Nachholbedarf von unterbliebenen Rentensenkungen abgebaut ist. Bis

\footnotetext{
${ }^{26}$ Tatsächlich ist gemäß Gleichung (15) bei einer geringeren Lohnzuwachsrate auch die Riester-Rente $p_{z}$ geringer. Berechnet man ausgehend von Gleichung (15) das Riester-Rentenniveau $p_{z} / y_{z}$, kann man aber zeigen, dass $p_{z}$ nicht im gleichen Ausmaß reduziert wird wie $y_{z}$ und somit eine geringere Lohnzuwachsrate mit einem höheren Riester-Rentenniveau einhergeht.
} 
das Nachholen abgeschlossen ist, ist das Rentenniveau höher. Entsprechend ist zunächst bei den Lohnwachstumsraten von 1,5\% bzw. 2,25\% die Rentenlücke nicht so hoch. Auch langfristig ergibt sich ein geringer Unterschied zwischen den Rentenlücken, was mit der Konstruktion der Rentenformel zu begründen ist. Bei höheren Lohnzuwachsraten ist die Dämpfungswirkung des Nachhaltigkeitsfaktors und des Riesterfaktors etwas stärker, ${ }^{27}$ so dass insgesamt das Rentenniveau bei höheren Lohnzuwachsraten etwas geringer und die Rentenniveaulücke etwas größer ist.

Das Riester-Rentenniveau unterscheidet sich ebenfalls nach der Lohnzuwachsrate, weil die Riester-Rente auf unterschiedlich hohe Lohnniveaus bezogen wird. Das Riester-Rentenniveau ist entsprechend bei einer Lohnzuwachsrate von 1,5\% am größten. Die Rentenlücke im Rentenzugangsjahr wird mehr als geschlossen (Abbildung 22).

\section{Abbildung 22: Rentenniveaulücke und Riester-Rentenniveau in Abhängigkeit von der unterstellten Lohnzuwachsrate}

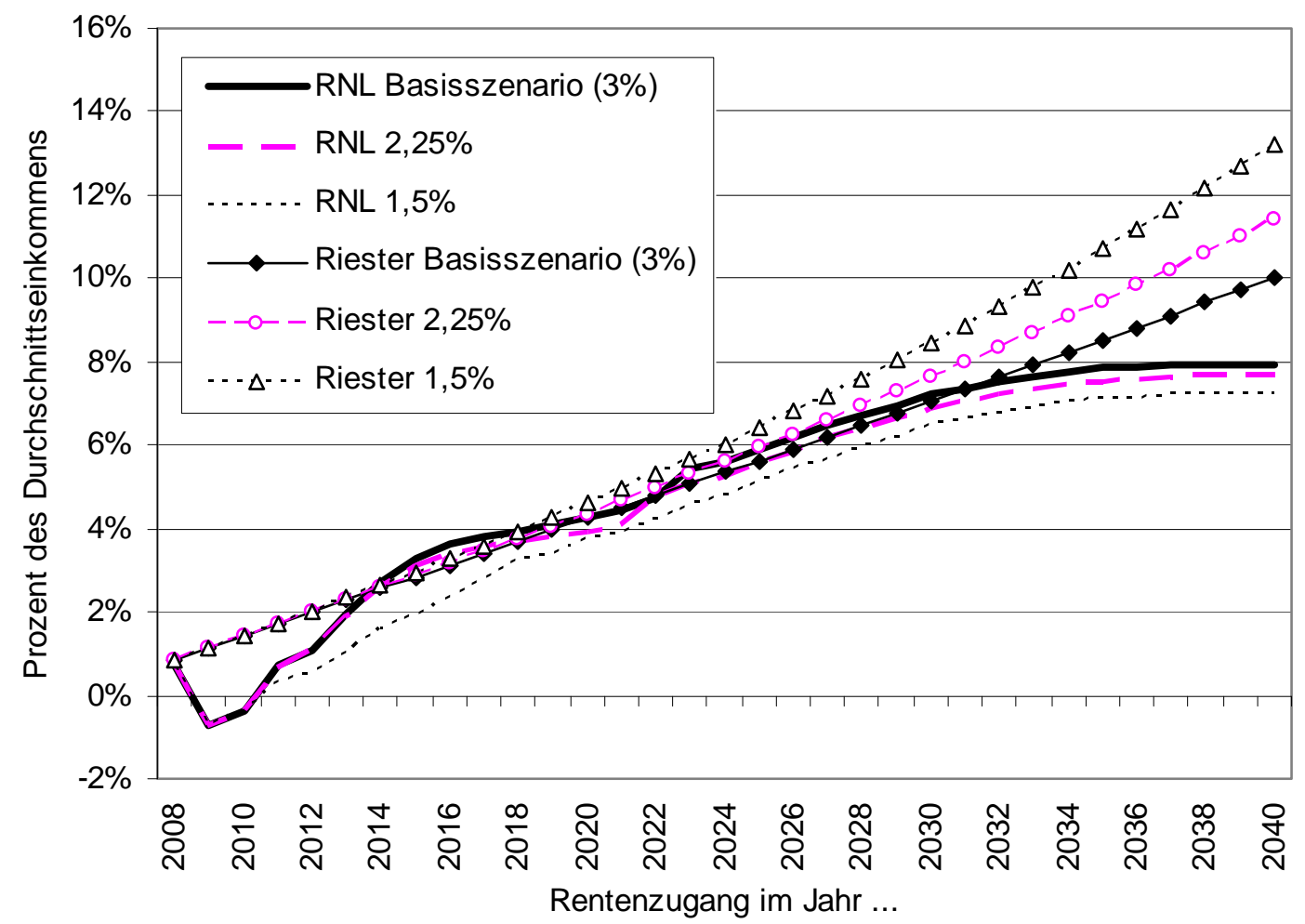

Quelle: eigene Berechnungen

\footnotetext{
${ }^{27}$ Ein Nachhaltigkeitsfaktor von beispielsweise 0,99 führt bei einem Lohnfaktor von 1,03 zu einem Abschlag von der Lohnzuwachsrate von 1,03 Prozentpunkten. Beträgt der Lohnfaktor nur 1,015 ist der Abschlag entsprechend nur 1,015 Prozentpunkte. Somit ist die Dämpfungswirkung des Nachhaltigkeitsfaktors bei höheren Lohnfaktoren größer.
} 
Die hier beschriebene Abhängigkeit von der Lohnentwicklung ist nichts anderes als die Abhängigkeit von der Renditedifferenz zwischen gesetzlicher Rente und der Riester-Rente. Die gesetzlichen Rentenansprüche verzinsen sich letztlich mit der Rentenanpassungsrate. Diese wird über die Rentenanpassungsformel eindeutig von der Lohnentwicklung bestimmt. Je größer die Differenz zwischen der Verzinsung der Riester-Rente und der Lohnzuwachsrate, desto höher ist der Anteil der Riester-Rente am Gesamtversorgungsniveau und desto eher kann die Riester-Rente die Rentenlücke schließen.

Wendet man die strenge Zieldefinition an und betrachtet die Rentenniveaus während der Rentenbezugszeit, dann zeigt sich, dass nur bei einer Lohnzuwachsrate von 1,5\% die Rentenlücke über die gesamte Rentenbezugszeit geschlossen werden kann und dies auch nur ab dem Rentenzugangsjahr 2030 (Abbildung 23). Ansonsten bestätigt sich der Befund, dass der Riester-Beitragssatz von 4\% ausreicht, um die Lücke bei Rentenzugang zu schließen. Um ein Gesamtrentenniveau von mindestens $48,4 \%$ zu gewährleisten, ist er jedoch zu gering.

\section{Abbildung 23: Rentenniveau während der Rentenbezugszeit in Abhängigkeit von der unterstellten Lohnzuwachsrate}

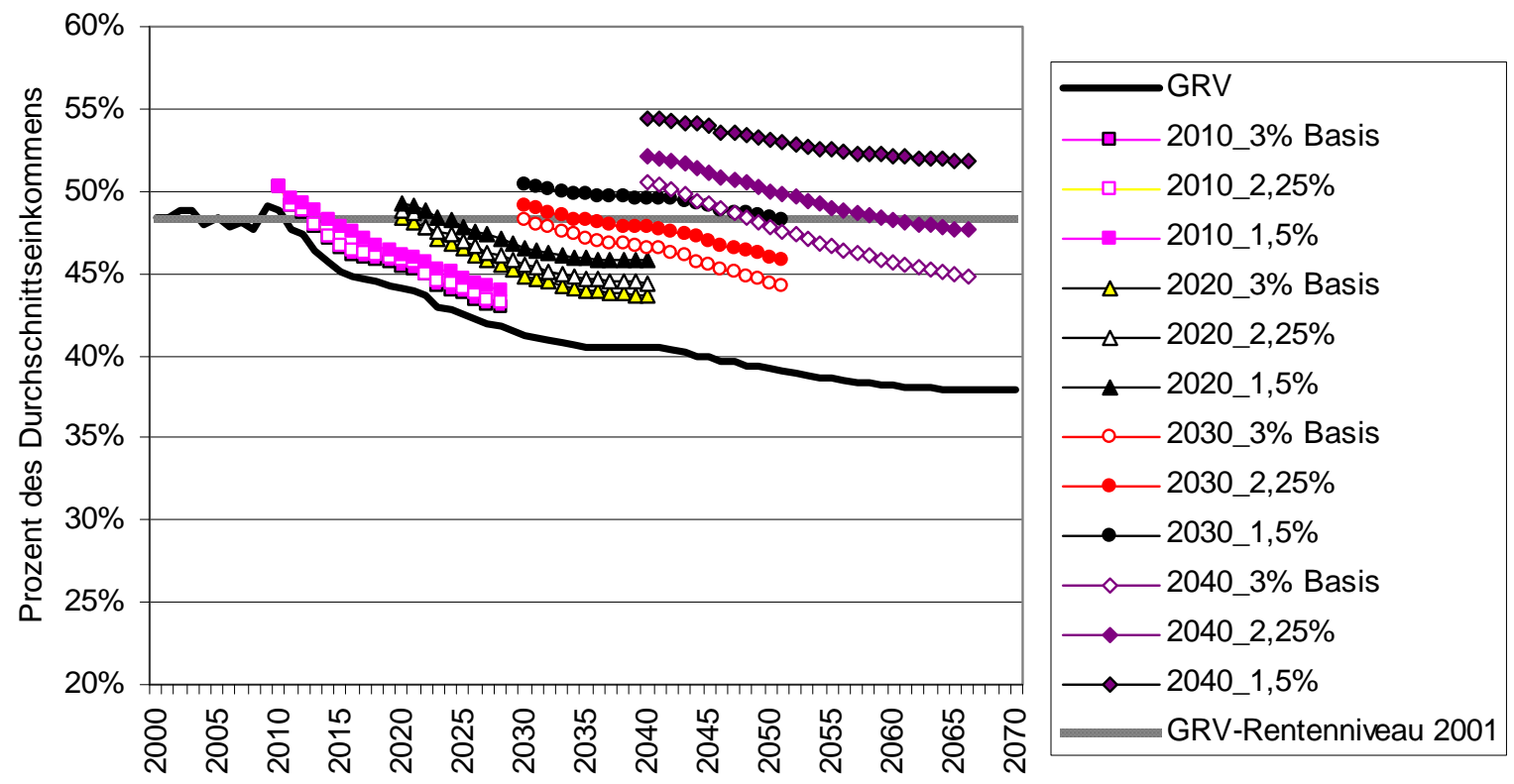

Quelle: eigene Berechnungen

Insgesamt kann man festhalten, dass die Rentenlücke umso eher geschlossen werden kann, je geringer die Lohnwachstumsrate ist. Will man nicht nur bei Renteneintritt das Bruttorentenniveau des Jahres 2001 realisieren, sondern während der gesamten Rentenbezugszeit, dann ist dies bei einem Riester-Beitragssatz von 4\% nur bei einer geringen Lohnzuwachsrate und für späte Rentenzugangsjahre etwa ab 2030 möglich. 


\section{Beitrag der „Rente mit 67“ zur Schließung der Rentenlücke}

Die Rentenreformen seit 2001 bestehen aus einem Dreiklang, der das Rentensystem zukunftsfest machen soll:

- Schaffung einer kapitalgedeckten Säule substitutiv für einen Teil der umlagefinanzierten Säule (Riester-Reform 2001),

- graduelle Reduktion des Rentenniveaus (Riester-Reform 2001 und Nachhaltigkeitsreform 2004),

- Anhebung des gesetzlichen Renteneintrittsalters („Rente mit 67“ 2007).

Die Anhebung des gesetzlichen Renteneintrittsalters, einhergehend mit einer Ausweitung der Erwerbszeit, impliziert höhere Rentenansprüche aus der gesetzlichen Rente. Damit ist die Rente mit 67 bei entsprechender Ausweitung der Erwerbszeit auch dazu geeignet, die durch die Riester- und Nachhaltigkeitsreform entstandene Rentenlücke zu schließen. Gemäß Altersgrenzenanpassungsgesetz wird ab 2012 das gesetzliche Renteneintrittsalter graduell von 65 Jahren auf 67 Jahre erhöht. Ab dem Geburtsjahrgang 1947 steigt es in jedem Jahr um einen Monat, so dass der Geburtsjahrgang 1958 ein gesetzliches Renteneintrittsalter von 66 Jahren hat. Danach erhöht sich das Regeleintrittsalter um 2 Monate jährlich. Damit gilt das neue gesetzliche Renteneintrittsalter von 67 Jahren erstmals für den Jahrgang 1964. Setzt man die Anhebung des gesetzlichen Renteneintrittsalters 1:1 in höheren Entgeltpunkten um, ergeben sich für einen Durchschnittsverdiener des Jahrgangs 1947 zusätzliche Entgeltpunkte in Höhe von 1/12, für den Jahrgang 1958 ein zusätzlicher Entgeltpunkt und für den Jahrgang 1964 zwei zusätzliche Entgeltpunkte.

Es zeigt sich, dass die zusätzliche Erwerbszeit durch die Rente mit 67 dazu geeignet ist, etwa ein Viertel der Rentenlücke zu decken (Abbildung 24). 


\section{Abbildung 24: Jahrgangsspezifische Rentenniveaulücke ${ }^{28}$ und zusätzliches Rentenniveau durch die Rente mit 67}

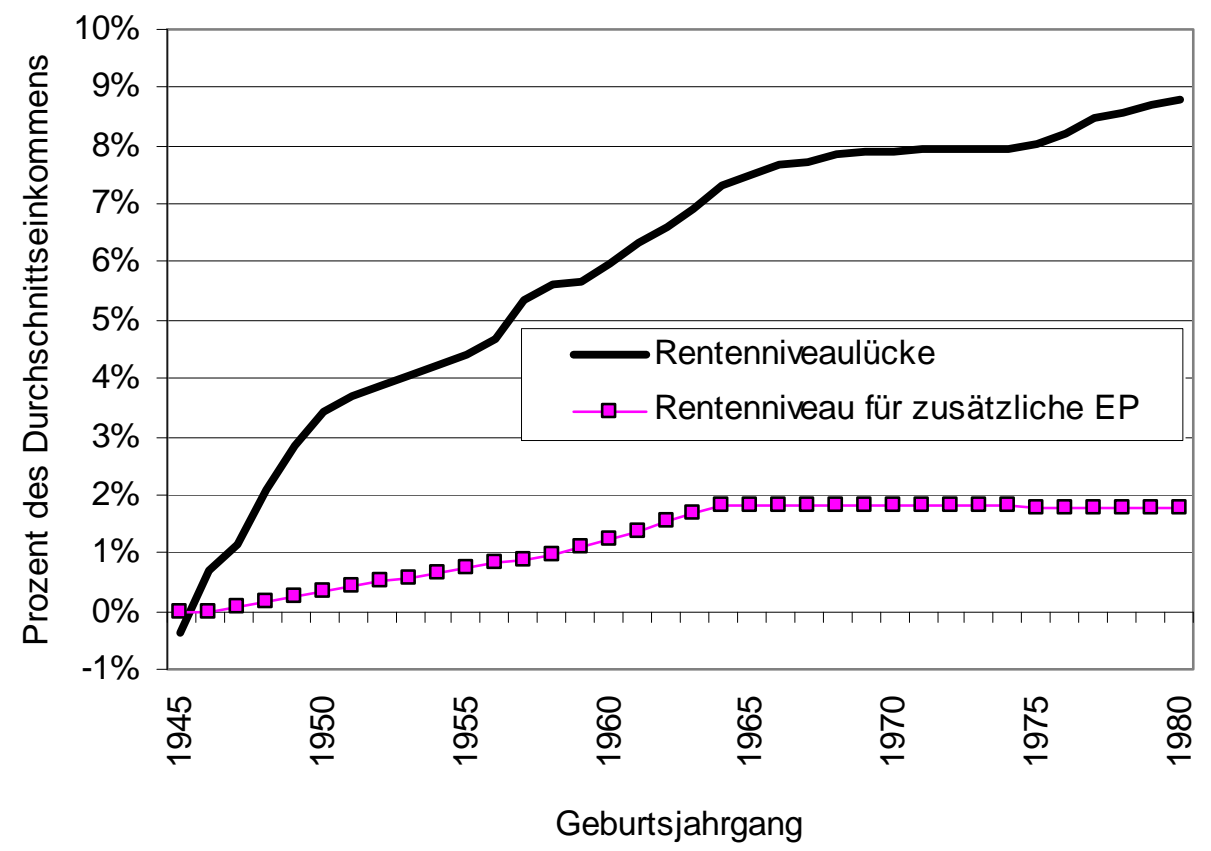

Quelle: eigene Berechnungen

\section{Fazit}

Mit der Riester-Rente sollte die durch die Rentenreformen 2001 und 2004 entstehende Rentenlücke in der gesetzlichen Rente gedeckt werden. Die Rentenlücke wird gemessen als Differenz zwischen der Rente, die man ohne die Rentenniveausenkungen durch die Reformen erhalten hätte im Vergleich zu der Rente, wenn die Reformen umgesetzt werden. Die Studie hat gezeigt, dass die Frage, ob das Schließen der Lücke gelingt, entscheidend von der Verzinsung der Riester-Rente, von den Kosten, von der Ansparzeit, von der Dynamisierung der Riester-Rente und der unterstellten Lebenserwartung sowie vom Riester-Beitragssatz abhängt. Unter plausiblen Annahmen kann man davon ausgehen, dass der RiesterBeitragssatz von 4\% zwar knapp bemessen ist, aber ausreicht, um die Lücke im Zugangsjahr zu decken. Wichtig ist allerdings, dass früh mit dem Sparen begonnen wird. Wer zwischen 2030 und 2040 in Rente geht, sollte 25 bis 30 Jahre 4\% seines Einkommens in seinen RiesterVertrag eingezahlt haben, will er die Rentenlücke schließen. Ob die Rentenlücke durch die Riester-Rente geschlossen werden kann, wird zudem entscheidend von der unterstellten zukünftigen Lohnentwicklung bestimmt. Fällt diese niedriger aus, macht die Riester-Rente

\footnotetext{
${ }^{28}$ Die jahrgangsspezifische Rentenniveaulücke wurde gemäß der Erhöhung des Renteneintrittsalters als gleitender Durchschnitt der Lücken in den jeweiligen Zugangsjahren gebildet.
} 
einen höheren Anteil an den Löhnen aus. Die Rentenniveaulücke kann dann durch die Riester-Rente leichter geschlossen werden.

Will man nicht nur im Rentenzugangsjahr sondern über die gesamte Rentenzeit ein Mindestverhältnis zwischen seiner Gesamtrente (gesetzliche Rente + Riester-Rente) und dem jeweils gültigen Durchschnittseinkommen aufrecht erhalten, wendet man also eine strenge Zieldefinition an, reicht ein jährlicher Riester-Sparbeitrag von 4\% des Bruttoeinkommens in der Regel nicht aus. Der Zielerreichungsgrad wird allerdings höher, je geringer die Lohnzuwachsrate ist. Insgesamt halten wir eine Lohnwachstumsrate von 3\%, selbst von 2,25\% für unrealistisch hoch. Selbst bei einer Lohnwachstumsrate von 1,5\%, die der Entwicklung der letzten 20 Jahre entspricht, würde ein jährlicher Riester-Sparbeitrag von 4\% des Bruttoeinkommens jedoch erst ab dem Jahrgang ausreichen, der im Jahr 2030 in Rente geht. Frühere Jahrgänge müssten zur strengen Deckung der Rentenlücke mehr als 4\% ansparen.

Die Verlängerung der Erwerbszeit im Sinne der „Rente mit 67“ trägt zusätzlich und signifikant zur Deckung der Lücke bei. Die durch die verlängerte Erwerbszeit zusätzlich erworbenen Rentenansprüche können bis zu einem Viertel der Lücke schließen. Damit zeigt sich einmal mehr, dass es der Kombination mehrerer rentenpolitischer Maßnahmen bedarf, um die Belastungen durch den demographischen Wandel aufzufangen.

\section{Literatur}

Börsch-Supan, A., Gasche, M. und C.B. Wilke (2009). Die Auswirkungen der Finanzkrise auf die Gesetzliche Rentenversicherung, ihre Beitragszahler und ihre Rentner, MEA-Study Nr. 9, Mannheim.

Börsch-Supan, A., Gasche, M. und M. Ziegelmeyer (2009): Auswirkungen der Finanzkrise auf die private Altersvorsorge, MEA-Diskussionspapier 193-2009, MEA Mannheim.

Börsch-Supan, A., Bucher-Koenen, T., Reil-Held,A. und C. Wilke (2008): Zum zukünftigen Stellenwert der ersten Säule im Gesamtsystem der Alterssicherung, MEA-Diskussionspapier 158-2008, MEA Mannheim.

Börsch-Supan A. und C.B. Wilke (2009): Zur mittel- und langfristigen Entwicklung der Erwerbstätigkeit in Deutschland, Zeitschrift für ArbeitsmarktForschung (ZAF), Volume 42, 1/2009, 29-48.

Börsch-Supan, A., Reil-Held, A. und C.B. Wilke (2003): Der Nachhaltigkeitsfaktor und andere Formelmodifikationen zur langfristigen Stabilisierung des Beitragssatzes zur GRV, Sozialer Fortschritt, Jg. 52, Heft 11-12 November/Dezember, 275-284.

Bundesministerium für Arbeit und Soziales (BMAS) (2009): Bericht der Bundesregierung über die gesetzliche Rentenversicherung, insbesondere über die Entwicklung der Einnahmen und Ausgaben, der Nachhaltigkeitsrücklage sowie des jeweils erforderlichen Beitragssatzes in 
den künftigen 15 Kalenderjahren gemäß § 154 SGB VI (Rentenversicherungsbericht 2009), Bonn.

Deutsche Aktuarvereinigung (DAV): Herleitung der DAV-Sterbetafel 2004R für

Rentenversicherungen, http://www.aktuar.de/download/dav/veroeffentlichungen/2004-UAGRentnersterblichkeit-DAV-2004R.pdf.

Essig, L. und A. Reil-Held (2003): Chancen und Risiken der „Riester-Rente“, MEADiskussionspapier 35-03, Uni-Mannheim.

Gasche, M. (2010): Rentenanpassung 2010 - Wem nützt die Rentengarantie?, MEADiskussionspapier 199-10, MEA Mannheim.

Gasche, M. (2009): Die sozialversicherungspflichtig Beschäftigten im deutschen Sozialversicherungssystem: Eigenschaften, Beitragsleistungen und Leistungsbezug, MEADiskussionspapier 189-09, MEA Mannheim.

Gasche, M. (2008): Erwerbsbiographie- und kohortenspezifische Versorgungsniveaus und Versorgungslücken in Deutschland, Allianz Dresdner Economic Research Working Paper 119, Frankfurt.

Kommission für die Nachhaltigkeit in der Finanzierung der Sozialen Sicherungssysteme (Rürup-Kommission) (2003): Bericht der Kommission.

Oehler, A. (2009): Alles „Riester“? Die Umsetzung der Förderidee in der Praxis - Stärken und Schwächen, Risiken und Chancen der staatlich geförderten kapitalgedeckten privaten Altersvorsorge von abhängig Beschäftigten (ohne Beamte) im Kontext der umlagefinanzierten gesetzlichen Rentenversicherung, Gutachten im Auftrag der Verbraucherzentrale Bundesverbandes e.V., Bamberg.

Statistisches Bundesamt (2009): Bevölkerung Deutschlands bis 2060 - 12. koordinierte Bevölkerungsvorausberechnung, Begleitmaterial zur Pressekonferenz am 18. November 2009 in Berlin.

Gasche, Martin (2010): Rentenanpassung 2010 - Wem nützt die Rentengarantie?, MEADiskussionspapier 199-10, MEA Mannheim.

Gasche, Martin (2009): Die sozialversicherungspflichtig Beschäftigten im deutschen Sozialversicherungssystem: Eigenschaften, Beitragsleistungen und Leistungsbezug, MEADiskussionspapier 189-09, MEA Mannheim.

Gasche, M. (2008): Erwerbsbiographie- und kohortenspezifische Versorgungsniveaus und Versorgungslücken in Deutschland, Allianz Dresdner Economic Research Working Paper 119, Frankfurt 02.10.2008.

Kommission für die Nachhaltigkeit in der Finanzierung der Sozialen Sicherungssysteme (Rürup-Kommission) (2003): Bericht der Kommission.

Oehler, A. (2009): Alles „Riester“? Die Umsetzung der Förderidee in der Praxis - Stärken und Schwächen, Risiken und Chancen der staatlich geförderten kapitalgedeckten privaten Altersvorsorge von abhängig Beschäftigten (ohne Beamte) im Kontext der umlagefinanzierten gesetzlichen Rentenversicherung, Gutachten im Auftrag der Verbraucherzentrale Bundesverbandes e.V., Bamberg, 7. Dezember 2009.

Statistisches Bundesamt (2009): Bevölkerung Deutschlands bis 2060 - 12. koordinierte Bevölkerungsvorausberechnung, Begleitmaterial zur Pressekonferenz am 18. November 2009 in Berlin. 


\section{Discussion Paper Series}

Mannheim Research Institute for the Economics of Aging, Universität Mannheim

To order copies, please direct your request to the author of the title in question.

\begin{tabular}{|c|c|c|c|}
\hline Nr. & Autoren & Titel & Jahr \\
\hline $189-09$ & Martin Gasche & $\begin{array}{l}\text { Die sozialversicherungspflichtig Beschäftigten } \\
\text { im deutschen Sozialversicherungssystem: } \\
\text { Eigenschaften, Beitragsleistungen und } \\
\text { Leistungsbezug }\end{array}$ & 09 \\
\hline $190-09$ & Martin Gasche & $\begin{array}{l}\text { Implizite Besteuerung im deutschen } \\
\text { Sozialversicherungssystem }\end{array}$ & 09 \\
\hline 191-09 & $\begin{array}{l}\text { Alexander Ludwig, } \\
\text { Alexander Zimper }\end{array}$ & $\begin{array}{l}\text { Biased Bayesian learning and the risk-free } \\
\text { rate puzzle }\end{array}$ & 09 \\
\hline $192-09$ & $\begin{array}{l}\text { Tabea Bucher- } \\
\text { Koenen }\end{array}$ & $\begin{array}{l}\text { Financial Literacy and Private Old-age } \\
\text { Provision in Germany - Evidence from SAVE } \\
2008 \text { - }\end{array}$ & 09 \\
\hline 193-09 & $\begin{array}{l}\text { Axel Börsch-Supan, } \\
\text { Martin Gasche, } \\
\text { Michael Ziegelmeyer }\end{array}$ & $\begin{array}{l}\text { Auswirkungen der Finanzkrise auf die private } \\
\text { Altersvorsorge }\end{array}$ & 09 \\
\hline 194-09 & Wolfgang Kuhle & The Optimum Structure for Government Debt & 09 \\
\hline $195-09$ & $\begin{array}{l}\text { Michela Coppola, } \\
\text { Anette Reil-Held }\end{array}$ & $\begin{array}{l}\text { Dynamik der Riester-Rente: Ergebnisse aus } \\
\text { SAVE } 2003 \text { bis } 2008\end{array}$ & 09 \\
\hline $196-10$ & $\begin{array}{l}\text { Alexander Ludwig, } \\
\text { Thomas Schelkle, } \\
\text { Edgar Vogel }\end{array}$ & $\begin{array}{l}\text { Demographic Change, Human Capital and } \\
\text { Welfare }\end{array}$ & 10 \\
\hline $197-10$ & $\begin{array}{l}\text { Axel Börsch-Supan, } \\
\text { Martin Gasche }\end{array}$ & Zur Sinnhaftigkeit der Riester-Rente & 10 \\
\hline $198-10$ & $\begin{array}{l}\text { Martin Gasche, } \\
\text { Michael Ziegelmeyer }\end{array}$ & $\begin{array}{l}\text { Verbreitung der Riester-Rente - Hat die } \\
\text { Finanz- und Wirtschaftskrise Spuren } \\
\text { hinterlassen? }\end{array}$ & 10 \\
\hline $199-10$ & Martin Gasche & $\begin{array}{l}\text { Rentenanpassung } 2010 \text { - Wem nützt die } \\
\text { Rentengarantie? }\end{array}$ & 10 \\
\hline $200-10$ & $\begin{array}{l}\text { Daniel Kemptner, } \\
\text { Hendrik Jürges, } \\
\text { Steffen Reinhold }\end{array}$ & $\begin{array}{l}\text { Changes in Compulsory Schooling and the } \\
\text { Causal Effect of Education on Health: } \\
\text { Evidence from Germany }\end{array}$ & 10 \\
\hline $201-10$ & $\begin{array}{l}\text { Axel Börsch-Supan, } \\
\text { Martin Gasche }\end{array}$ & $\begin{array}{l}\text { Kann die Riester-Rente die Rentenlücke in der } \\
\text { gesetzlichen Rente schließen? }\end{array}$ & 10 \\
\hline
\end{tabular}

